\title{
Consenso sobre a terminologia padronizada do processo de cuidado em nutrição para pacientes adultos com doença renal crônica
}

\author{
Consensus on standardized terminology of the nutrition care process for adult patients with chronic \\ kidney disease
}

DOI: $10.37111 /$ braspenj.AE202035401

Cristina Martins $s^{1,2,3,4}$

Simone L. Saeki ${ }^{3}$

Marcelo Mazza do Nascimento 2

Fernando Lucas Júnior²

Maria Vavruk ${ }^{3}$

Christiane L. Meireles ${ }^{3}$

Sandra Justino 3

Denise Mafra ${ }^{2}$

Estela Iraci Rabito ${ }^{3}$

Maria Eliana Madalozzo Shieferdecker ${ }^{3}$

Letícia Fuganti Campos ${ }^{5}$

Denise P. J. van Aanholt ${ }^{5}$

Ana Adélia Hordonho 1,2

Márcia Samia Fidelix ${ }^{2}$

\section{Unitermos:}

Ciências da Nutrição. Desnutrição. Insuficiência Renal Crônica. Terminologia. Apoio Nutricional.

\section{Keywords:}

Nutritional Sciences. Malnutrition. Renal Insufficiency, Chronic. Terminology. Nutritional Support.

\section{Endereço para correspondência:}

Leticia Fuganti Campos

Rua Abílio Soares, 233 - ci 144 - Paraíso - São Paulo, SP, Brasil - CEP 04005-000

E-mail: le_campos@hortmail.com

\section{Submissão}

22 de setembro de 2020

Aceito para publicação

26 de novembro de 2020

\begin{abstract}
RESUMO
Este consenso representa a primeira colaboração entre três organizações profissionais com foco em nutrição: Associação Brasileira de Nutrição (ASBRAN), Sociedade Brasileira de Nefrologia (SBN) e Sociedade Brasileira de Nutrição Parenteral e Enteral (Braspen/SBNPE), com o objetivo de identificar a terminologia e instrumentos padronizados internacionalmente para o processo de cuidado em nutrição. $O$ foco é facilitar a condução de treinamentos de nutricionistas que trabalham com pacientes adultos com doenças renais crônicas (DRC). Foram levantadas 11 questões relacionadas à triagem, ao processo de cuidado e à gestão de resultados em nutrição. As recomendações foram baseadas em diretrizes internacionais e em bancos de dados eletrônicos, como PubMed, EMBASE ${ }^{\mathrm{T}}$, CINHAL, Web of Science e Cochrane. A partir do envio de listas de termos padronizados internacionalmente, 20 nutricionistas especialistas selecionaram aqueles que consideraram muito claros e relevantes para a prática clínica com pacientes ambulatoriais com DRC. Foi calculado o índice de validade de conteúdo (IVC), com $80 \%$ de concordância nas respostas. $O$ Grading of Recommendations, Assessment, Development and Evaluation (GRADE) foi usado para atribuir força de evidência às recomendações. Foram selecionados 107 termos de Avaliação e Reavaliação, 28 de Diagnóstico, 9 de Intervenção e 94 de Monitoramento e Aferição em Nutrição. A lista de termos selecionados e identificação de instrumentos auxiliará no planejamento de treinamentos e na implementação de terminologia padronizada em nutrição no Brasil, para nutricionistas que trabalham com pacientes renais crônicos.
\end{abstract}

\section{ABSTRACT}

This consensus represents the first collaboration between three professional organizations focused on nutrition: Brazilian Association of Nutrition (ASBRAN), Brazilian Society of Nephrology (SBN) and Brazilian Society of Parenteral and Enteral Nutrition (Braspen/SBNPE), with the objective of identifying internationally standardized terminology and instruments for the nutrition care process. The focus is to facilitate the training of nutritionists who work with adult patients with chronic kidney diseases (CKD). Eleven issues related to nutrition screening, care and management of outcomes were raised. Recommendations were based on international guidelines and electronic databases such as PubMed, EMBASE ${ }^{\mathrm{T}}{ }, \mathrm{CINHAL}$, Web of Science and Cochrane. From the sending of lists of internationally standardized terms, 20 nutrition specialists selected those they considered very clear and relevant for clinical practice with CKD outpatients. The content validity index (CVI) was calculated, with $80 \%$ agreement in the responses. The Grading of Recommendations, Assessment, Development and Evaluation (GRADE) was used to assign evidence strength to the recommendations. A total of 107 terms were selected for Nutrition Assessment and Reassessment, 28 for Nutrition Diagnosis, 9 for Nutrition Intervention, and 94 for Nutrition Monitoring and Evaluation in Nutrition. The list of selected terms and identification of instruments will assist in training planning and implementation of standardized nutrition terminology in Brazil for nutritionists working with CKD patients.

Associação Brasileira de Nutrição (ASBRAN).

2. Sociedade Brasileira de Nefrologia (SBN) - Comitê de Nutrição.

3. Consórcio de Pesquisa e Implementação da TPCN no Brasil.

4. Grupo de Trabalho Internacional da NCPT/Subcomitê Internacional da Academy of Nutrition and Dietetics (Academy) para a TPCN.

5. Sociedade Brasileira de Nutrição Parenteral e Enteral (Braspen/SBNPE). 


\section{INTRODUÇ̃̃O}

O estado nutricional tem papel fundamental na saúde e nos desfechos clínicos de pacientes com doença renal crônica (DRC). É amplamente conhecido que a desnutrição tem alta prevalência e está intimamente associada a resultados clínicos adversos e aumento da taxa de hospitalização, complicações e mortalidade nessa população ${ }^{1,2}$. A patogênese da desnutrição na DRC é multifatorial e complexa, e as principais causas são a redução da ingestão alimentar e do anabolismo de nutrientes, e a presença de hipercatabolismo ${ }^{1-3}$.

Para documentar claramente o impacto do cuidado em nutrição, é imprescindível o uso de terminologia e de instrumentos padronizados, capazes de capturar as especificidades dos cuidados e serem codificados. Com isso, há facilitação de análise em pesquisas e bancos de dados informatizados, e a comunicação em prontuários eletrônicos. Exemplos de busca de padronização em nefrologia são os consensos e diretrizes KDIGO (Kidney Disease Improving Global Outcomes) e KDOQI (Kidney Disease Outcomes Quality Initiative). Há, inclusive, publicação recente sobre a nomenclatura recomendada para as enfermidades renais com objetivo de melhorar a comunicação entre os profissionais e a população ${ }^{4}$.

O uso de termos pré-determinados e de dados exatos possibilita a compreensão sobre a ligação entre os problemas, as intervenções específicas e os desfechos significativos alcançados na nutrição e na saúde. Portanto, somente a partir do uso de terminologia e instrumentos padronizados torna-se possível capturar ações de forma consistente e apresentar desfechos positivos sobre as intervenções mais importantes da nutrição e da saúde dos pacientes.

A Classificação Internacional de Doenças (CID-10), baseada na Organização Mundial da Saúde, é o sistema oficial de designação de códigos para o diagnóstico e procedimentos médicos. Embora existam conceitos de nutrição incluídos nessa terminologia, eles são insuficientes para identificar problemas nutricionais e intervenções específicas, fornecidas pelo nutricionista. Por exemplo, a área da enfermagem é vastamente diferente daquela do médico, e ambas são diferentes das necessidades de outros profissionais da saúde.

Há terminologias internacionais designadas para prontuários eletrônicos em saúde e que oferecem potencial para inclusão de termos de nutrição. Um exemplo é a SNOMEDCT (Systematized Nomenclature of Medicine-Clinical Terms) (http://www.snomed.org/), mantida desde 2007 pela Organização Internacional para o Desenvolvimento de Normas de Terminologia em Saúde (International Health Terminology Standards Development Organization - IHTSDO). Inicialmente foi desenvolvida para doenças, mas evoluiu consideravelmente e, recentemente, incluiu termos de outras áreas de conhecimento, como enfermagem e nutrição. A SNOMED-CT é considerada a terminologia em saúde mais completa e precisa do mundo. O Brasil se tornou membro da SNOMED Internacional em 2018. Portanto, é de interesse nacional a padronização de terminologias clínicas, incluindo as relacionadas à nutrição.

Em nefrologia, é frequente a transferência de pacientes de nível ambulatorial para unidades hospitalares, e vice-versa. Portanto, a padronização de termos e de instrumentos de nutrição, principalmente para uso em prontuários e registros eletrônicos de saúde, otimiza o compartilhamento de dados e a comunicação entre instituições, melhora a qualidade dos dados e os desfechos de intervenções, aumenta a segurança do paciente com a melhor continuidade dos cuidados, reduz a duplicação de serviços e, por fim, economiza tempo de trabalho profissional e recursos financeiros. Entretanto, além de ainda não haver terminologia padronizada em nutrição no Brasil, os prontuários eletrônicos não estão desenvolvidos para a entrada estruturada (sem texto livre) de dados. Ambos os processos são importantes e desafiadores, e necessitam de planejamento e soluções.

O objetivo deste consenso foi identificar termos selecionados em nutrição, a partir da terminologia internacional, que possam facilitar o treinamento de nutricionistas especializados em nutrição renal no Brasil. Também foi objetivo identificar instrumentos de triagem e de diagnóstico de desnutrição validados, que possam ser padronizados na prática profissional desses nutricionistas. Portanto, a população-alvo desse consenso são os nutricionistas que trabalham com pacientes com DRC adultos (>18 anos), ambulatoriais em estágio não-dialítico, hemodiálise (HD), diálise peritoneal (DP) ou transplante renal.

\section{QUESTÕES}

Onze questões foram identificadas, sob três tópicos, descritas abaixo. Foi utilizada a edição 2019 da Terminologia do Processo de Cuidado em Nutrição (TPCN) traduzida para o Português, com validação da tradução por dois revisores, nutricionistas, com português como língua nativa, de acordo com os critérios da Academy of Nutrition and Dietetics (Academy).

\section{Tópico: Sistema de Triagem e Referência para Pacientes com DRC}

1. Qual instrumento de triagem de desnutrição é recomendado?

\section{Tópico: Processo de Cuidado em Nutrição para Pacientes com DRC}

2. A padronização do Processo de Cuidado em Nutrição (PCN) e a Terminologia do Processo de Cuidado em Nutrição (TPCN) é recomendada?

3. Quais termos padronizados de Avaliação e Reavaliação em Nutrição são considerados muito relevantes por nutricionistas especialistas? 
4. Quais termos padronizados de Diagnóstico em Nutrição são considerados muito relevantes por nutricionistas especialistas?

5. A definição da desnutrição baseada na etiologia é recomendada?

6. Qual instrumento de diagnóstico de desnutrição é recomendado?

7. Quais termos padronizados de Intervenção em Nutrição são considerados muito relevantes por nutricionistas especialistas?

8. Quais padrões de referência para ingestão diária de nutrientes e de alimentos são recomendados?

9. Quais termos padronizados de Monitoramento e Aferição em Nutrição são considerados muito relevantes por nutricionistas especialistas?

\section{Tópico: Sistema de Gestão de Resultados para Pacientes com DRC}

10. Qual formato para documentação de dados do PCN é recomendado?

11. Quais indicadores de gestão de resultados em nutrição são recomendados?

Especificamente para responder às questões sobre seleção de termos, foram escolhidos nutricionistas experientes (pelo menos dois anos de prática) em atendimento ambulatorial de pacientes com DRC. Os nutricionistas especialistas receberam, via e-mail, listas dos termos da TPCN. Foi solicitado que, individualmente, cada nutricionista selecionasse os termos considerados muito relevantes e muito claros para a prática clínica com pacientes com DRC ambulatoriais. As respostas foram computadas em planilha contendo todos os códigos da TPCN.

Para determinação e quantificação da validade do conteúdo, foi calculado o índice de validade de conteúdo $(\mathrm{IVC})^{5,6}$. Neste, a escala varia de 1 a 4 , sendo: 1 = Não relevante/Não claro; $2=U \mathrm{~m}$ pouco relevante/Um pouco claro; 3 = Bastante relevante/Bastante claro; e 4 = Muito relevante/Muito claro. Devido ao grande número de termos padronizados, foi solicitado que os nutricionistas especialistas escolhessem somente os termos referentes ao número de respostas " 4 ": IVC = número de respostas " 4 "/ número total de respostas.

Pelo fato de ter havido participação de mais de seis especialistas nas respostas, foi estipulada a taxa de concordância de $80 \%$ como representativa do grupo 7,8 .

\section{Níveis de Evidência}

As recomendações deste documento foram adaptadas de consensos e diretrizes internacionais, sendo referidas quando utilizadas. Quando questões não foram respondidas por diretrizes ou consensos internacionais, foi realizada pesquisa bibliográfica (até 31 de agosto de 2020) por meio de banco de dados eletrônicos, como PubMed, EMBASE ${ }^{\mathrm{TM}}$, CINHAL, Web of Science e Cochrane, para identificar artigos relevantes. As evidências nas diretrizes, consensos e literatura foram discutidas e tabuladas em tabela de evidências, e as recomendações foram elaboradas. Um consenso entre o grupo de trabalho foi utilizado para as áreas de evidências inconclusivas ou insuficientes.

O Sistema Grading of Recommendations, Assessment, Development and Evaluation (GRADE) ${ }^{9}$ foi usado para atribuir força de evidência (Quadro 1). O sistema GRADE é amplamente utilizado e é considerado metodologicamente rigoroso e fácil de usar.

Quadro 1 - Sistema Grading of Recommendations, Assessment, Development and Evaluation (GRADE) ${ }^{9}$.

\begin{tabular}{lccc}
\hline $\begin{array}{l}\text { Nível de } \\
\text { evidência }\end{array}$ & $\begin{array}{c}\text { Definição da } \\
\text { evidểncia }\end{array}$ & Observações & $\begin{array}{c}\text { Fonte de } \\
\text { informação }\end{array}$ \\
\hline
\end{tabular}

A- Há forte con- É improvável Ensaios clínicos

Alto fiança de que o que trabalhos bem delineados, verdadeiro efeito adicionais com amostra repreesteja próximo modificarão a sentativa. daquele estima- confiança na $\mathrm{Em}$ alguns casos, do estimativa do estudos observaefeito cionais bem delineados, com achados consistentes ${ }^{*}$

B- Há confiança Trabalhos fu- Ensaios clíniModerado moderada no turos poderão cos com leves** efeito estimado modificar a limitações. confiança na Estudos observacioestimativa de nais bem delineaefeito, poden- dos, com achados do, inclusive, consistentes* modificar a estimativa

\begin{tabular}{|c|c|c|c|}
\hline $\begin{array}{l}\text { C- } \\
\text { Baixo }\end{array}$ & $\begin{array}{l}\text { A confiança no } \\
\text { efeito é limitada }\end{array}$ & $\begin{array}{l}\text { Trabalhos fu- } \\
\text { turos prova- } \\
\text { velmente terão } \\
\text { um impacto } \\
\text { importante na } \\
\text { confiança da } \\
\text { estimativa de } \\
\text { efeito }\end{array}$ & $\begin{array}{l}\text { Ensaios clínicos } \\
\text { com limitações } \\
\text { moderadas**. } \\
\text { Estudos observa- } \\
\text { cionais comparati- } \\
\text { vos: coorte e caso } \\
\text { controle }\end{array}$ \\
\hline $\begin{array}{l}\text { D- } \\
\text { Muito } \\
\text { baixo }\end{array}$ & $\begin{array}{l}\text { A confiança na } \\
\text { estimativa de } \\
\text { efeito é mui- } \\
\text { to limitada. Há } \\
\text { importante grau } \\
\text { de incerteza nos } \\
\text { achados }\end{array}$ & $\begin{array}{l}\text { Qualquer esti- } \\
\text { mativa de efeito } \\
\text { é limitada }\end{array}$ & $\begin{array}{l}\text { Ensaios clínicos } \\
\text { com limitações gra- } \\
\text { ves }^{\star \star} \text {. } \\
\text { Estudos observacio- } \\
\text { nais comparativos, } \\
\text { com presença de } \\
\text { limitações }{ }^{\star \star} \text {. } \\
\text { Estudos observa- } \\
\text { cionais não compa- } \\
\text { rados }{ }^{\star \star *} \text {. } \\
\text { Opinião de espe- } \\
\text { cialistas }\end{array}$ \\
\hline
\end{tabular}

https://www.gradeworkinggroup.org/

*Estudos de coorte sem limitações metodológicas, com achados consistentes, apresentando tamanho de efeito grande e/ou gradiente dose-resposta.

**Limitações: vieses no delineamento do estudo, inconsistência nos resultados, desfechos substitutos ou validade externa comprometida.

${ }^{* \star *}$ Séries e relatos de casos. 
A força da recomendação (Quadro 2) foi baseada em discussão de consenso, que incluiu a expressão e deliberação de opiniões de especialistas, relação risco-benefício da recomendação, custos e revisão de evidências de suporte, seguidas pelo uso do método Delphi e votos, até que a concordância fosse alcançada.

Quadro 2 - Força da recomendação.

\section{Força da recomendação}

\begin{tabular}{l|l}
\hline 1. Forte & Recomendamos/não recomendamos \\
\hline 2. Fraco & Sugerimos/não sugerimos \\
\hline
\end{tabular}

\section{RECOMENDAÇÕES PARA O SISTEMA DE TRIAGEM E REFERÊNCIA}

\section{Recomendação 1}

O Instrumento de Triagem de Desnutrição, conhecido como MST (Malnutrition Screening Tool), é recomendado para a triagem de risco de desnutrição para pacientes com DRC. A triagem deve ser aplicada, pelo menos, mensalmente.

Nível de evidência A, Força 1

\section{Comentário}

O Sistema de Triagem e Referência é uma estrutura de suporte ao PCN. A triagem identifica pacientes em risco de desnutrição e pode ser realizada em qualquer ambiente de prática clínica. Além do nutricionista, pode ser executada por indivíduo treinado (médico, enfermeiro, técnico de nutrição, estagiários, familiares, próprio paciente, entre outros) $)^{10,11}$. Pode ser útil para pacientes que se beneficiariam da avaliação, diagnóstico e intervenção do nutricionista. Além da triagem, o paciente pode ser referenciado para entrada no PCN.

Há inúmeros instrumentos de triagem de risco nutricional desenvolvidos e/ou validados para pacientes com DRC. Exemplos são o Índice Geriátrico de Risco Nutricional (Geriatric Nutritional Risk Index - GNRI), validado para pacientes em HD ${ }^{12}$ e em DP'13, o NRS-2002 (Triagem de Risco Nutricional-2002 - Nutritional Risk Screening), validado para pacientes em HD ${ }^{14}$ e o R-NST (Instrumento de Triagem Nutricional Renal - Renal Nutrition Screening Tool), validado para pacientes renais hospitalizados ${ }^{15}$.

De maneira ideal, um instrumento deve ser independente da doença, idade ou local de aplicação para reconhecer o risco de desnutrição. Ou seja, não deve ser específico para uma população clínica, mas validado para uso universal. Por isso, este consenso apoia a revisão sistemática de Skipper et al. ${ }^{16}$ e a posição mais recente da Academy ${ }^{10}$, que indicam o MST (Malnutrition Screening Tool - Instrumento de Triagem de Desnutrição) (Quadro 3) como aquele com os melhores graus de validade, concordância e confiabilidade, independentemente de idade, história clínica ou local de atendimento do paciente. O MST foi validado, com boa generalização, para pacientes em cuidados agudos, em longo prazo, em reabilitação, ambulatorial e em oncologia em, pelo menos, nove países diferentes ${ }^{17-35}$.

Quadro 3 - Instrumento de Triagem de Desnutrição (Malnutrition Screening Tool-MST).

\begin{tabular}{lc}
\hline Questões & Pontuação \\
\hline 1) Você teve perda recente e não & \\
intencional de peso? & \\
- Não & 2 \\
- Não sabe & \\
\hline 2) Se sim, de quanto (em kg) foi a sua & \\
perda de peso? & 1 \\
- $1-5$ & 2 \\
- $6-10$ & 3 \\
- $11-15$ & 4 \\
- Não sabe & 2 \\
\hline 3) Você tem se alimentado mal devido à & \\
redução do apetite? & 0 \\
- Não & 1 \\
- Sim & Somatória: \\
\hline Interpretação: $\geq 2$ = risco de desnutrição & \\
\hline
\end{tabular}

Adaptado de Ferguson et al. ${ }^{38}$.

O KDOQI não sugere instrumento específico para triagem de risco de desnutrição, mas recomenda que seja realizada, pelo menos, bianualmente para pacientes com DRC 3-5, inclusive em diálise e pós transplante ${ }^{36}$.

A simplicidade do MST permite que o instrumento seja aplicado pelo próprio paciente, familiares e cuidadores, além de profissionais da saúde. Estudo demonstrou que o MST foi confiável e válido para identificar, com acurácia, o risco de desnutrição quando conduzido por pacientes ambulatoriais com câncer, comparado ao instrumento sendo aplicado por nutricionistas ${ }^{37}$.

Portanto, pelo fato de a desnutrição ser um grande risco para pacientes com DRC e estar altamente relacionada com morbidade e mortalidade, este consenso recomenda que a triagem seja feita, pelo menos, mensalmente, visto que pode ser aplicada pelo próprio paciente ou cuidadores. Este consenso também sugere campanhas voltadas para pacientes e profissionais para a aplicação frequente do MST. 


\section{RECOMENDAÇÕES PARA O PROCESSO DE CUIDADO EM NUTRIÇÃO}

\section{Recomendação 2}

A padronização do Processo de Cuidado em Nutrição (PCN) e a Terminologia do Processo de Cuidado em Nutrição (TPCN) são recomendados para pacientes com DRC.

Nível de evidência B, Força 1

\section{Comentários}

O Processo de Cuidado em Nutrição (PCN), adotado pela Academy ${ }^{39}$, é uma abordagem sistemática, completa e profunda para coletar, verificar, classificar, interpretar e documentar dados. É composto de quatro passos, cada um organizado por categorias, e em classes e subclasses ${ }^{40}$. Os passos são: Avaliação e Reavaliação, Diagnóstico, Intervenção, e Monitoramento e Aferição em Nutrição. $\bigcirc$ nutricionista deve, obrigatoriamente, aplicar os quatro passos do PCN. Cada passo deve ser concluído antes de avançar para o próximo.

A Terminologia do Processo de Cuidado em Nutrição (TPCN) é a linguagem profissional que padroniza e codifica termos específicos ${ }^{40}$. É um vocabulário controlado, que complementa o PCN. A TPCN é um sistema organizado em estrutura hierárquica, capaz de fornecer descrição acurada e específica de serviços realizados pelo nutricionista (Figura 1). A TPCN tem o objetivo de melhorar a qualidade do cuidado e os desfechos relacionados ${ }^{40}$.
A aplicação da TPCN tem sido relatada em práticas e ambientes educacionais ${ }^{41-47}$, em diversas partes do mundo ${ }^{48,49}$. A implementação está associada a inúmeras vantagens. Com ela, cria-se uma estrutura comum para os cuidados de rotina e a pesquisa em nutrição. Além disso, a terminologia padronizada pode promover o pensamento crítico e a documentação mais focada e produtiva, que pode melhorar a comunicação entre profissionais.

A Academy, juntamente com organizações profissionais internacionais, tem dedicado grandes esforços para tornar a TPCN a linguagem global. Os termos são atualizados uma vez ao ano e disponibilizados via plataforma web. Também, a TPCN vem sendo ajustada para compactuar com sistemas internacionais de saúde e com diretrizes baseadas em evidências ${ }^{46,50-52}$. Desde 2011, os termos de todos os passos do PCN estão sendo incluídos em grandes padrões internacionais interdisciplinares, como a SNOMED-CT53. Estes são terminologias clínicas padronizadas, requeridas em prontuários eletrônicos de diversos países. Embora já traduzidos para diversas línguas e dialetos, estudo demonstra que o PCN e a TPCN ainda não foram totalmente adotados na prática clínica de nutricionistas que trabalham com DRC devido, principalmente, à falta de informaçãa ${ }^{54}$.

A ASBRAN, em 2014, deu o primeiro passo rumo à padronização internacional, e publicou o Manual Orientativo: Sistematização do Cuidado em Nutrição (SICNUT) ${ }^{55}$. No Manual, foram recomendados os diagnósticos em nutrição, propostos pela Academy. Desde 2015, a ASBRAN mantém parceria com a Academy, com representante no Subcomitê Internacional para a TPCN. De 2016 a 2018, o manual completo da PCN e TPCN foi traduzido e validado para o português, dentro dos critérios da Academy. Em 2020, foi

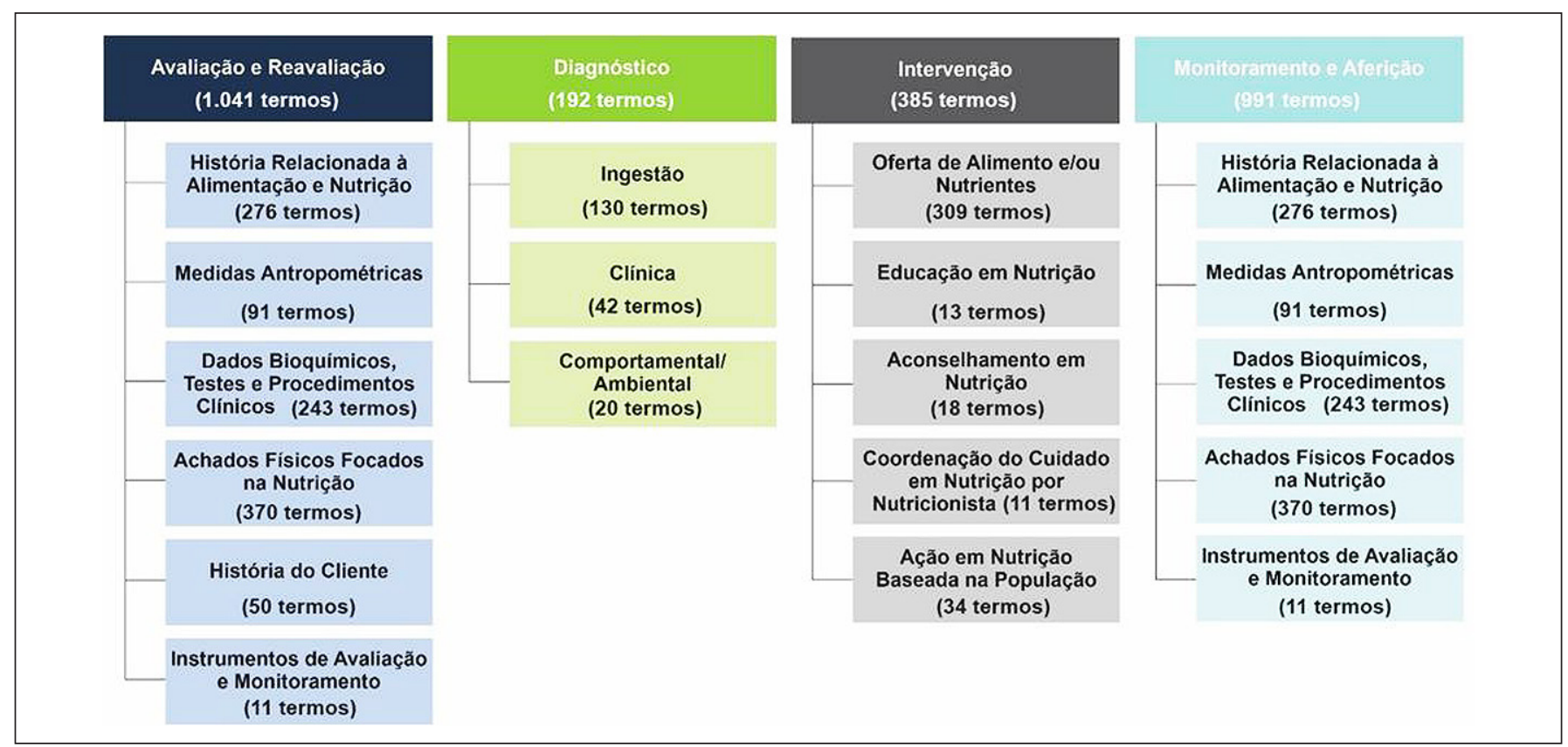

Figura 1 - Categorias padronizadas para as quatro etapas do Processo de Cuidado em Nutrição, versão 201940, com número de termos em cada. 
criado o Consórcio de Pesquisa e Implementação da TPCN no Brasil, que elegeu a Universidade Federal do Paraná (UFPR) como o primeiro Centro de Referência para pesquisa e treinamento da NCPT no País. O desenvolvimento de consensos em áreas de especialidade da nutrição faz parte de um braço do planejamento estratégico do Consórcio.

A partir da padronização da TPCN no Brasil, há possibilidade de implantação do Nutrition and Dietetics Health Informatics Infrastructure (ANDHII ${ }^{\circledR}$ ), também desenvolvido pela Academy, que é uma plataforma de agregação de dados via web ${ }^{53}$. O ANDHII ${ }^{\circledR}$ é baseado na NCPT, tem formato fácil de ser integrado a outros sistemas informatizados de saúde e tem custo relativamente baixo. Além dos EUA, é usado na área da educação, pesquisa e prática clínica e de saúde pública de diversos países ${ }^{53}$. A utilização de um sistema informatizado único pode significar, sem dúvida, economia expressiva de tempo e de recursos para clínicas de diálise, hospitais, ambulatórios, consultórios e demais serviços de saúde. Além disso, pode constituir grande avanço para a pesquisa local e mundial na área da nutrição e saúde.

\section{Recomendação 3}

Do total de 1.041 termos de Avaliação e Reavaliação em Nutrição padronizados internacionalmente, 107 são recomendados para treinamento inicial de nutricionistas que trabalham com pacientes com DRC no Brasil.

Nível de evidência C, Força 1

\section{Comentários}

A Avaliação e Reavaliação é uma abordagem sistemática para coletar, classificar e sintetizar dados nutricionais. O objetivo é descrever o estado nutricional e os problemas relacionados à nutrição e suas etiologias ${ }^{40}$. Os dados são comparados a critérios ou normas, a padrões de referência relevantes (nacionais, internacionais ou regulatórios) ou a metas estabelecidas pelo profissional e paciente. Também podem ser usados na gestão da qualidade do cuidado em nutrição.

A etiologia direciona a intervenção, que deve resolver ou minimizar o diagnóstico em nutrição. A busca pela etiologia é parte importante da Avaliação e Reavaliação em Nutrição, pois ela é particularmente útil em ligar o diagnóstico em nutrição à intervenção $0^{53}$. A TPCN padroniza e codifica etiologias, permitindo identificar os tipos de intervenções que, efetivamente, resolvem problemas específicos. Um mesmo diagnóstico em nutrição pode ter diferentes etiologias.

A TPCN engloba grande número de termos que apoiam as habilidades e funções de nutricionistas em todas as áreas de atuação, como neonatologia, saúde pública, esportes, além de nutrição clínica. Pelo fato de ainda não ser comumente utilizada, inclusive em nefrologia, o estreitamento de termos pode facilitar o treinamento profissional e a implementação da TPCN. A Tabela 1 apresenta a seleção de termos de Avaliação e Reavaliação considerados essenciais por nutricionistas especialistas em pacientes com DRC.

Tabela 1 - Termos de Avaliação e Reavaliação em Nutrição considerados essenciais por nutricionistas especialistas em doença renal.

\begin{tabular}{|c|c|c|c|}
\hline Categorias/Termos & Código & Tratamento & Código \\
\hline $\begin{array}{l}\text { DOMÍNIO: HISTÓRIA RELACIONADA À } \\
\text { ALIMENTAÇÃO E NUTRIÇÃO (FH) }\end{array}$ & \multicolumn{3}{|c|}{ MEDIDAS ANTROPOMÉTRICAS (AD) } \\
\hline Ingestão total de energia & $\mathrm{FH}-1.1 .1 .1$ & Estatura medida & $A D-1.1 .1 .1$ \\
\hline Líquidos orais & $\mathrm{FH}-1.2 .1 .1$ & Altura do joelho & $A D-1.1 .1 .10$ \\
\hline Quantidade de alimento & $\mathrm{FH}-1.2 .2 .1$ & Peso medido & $A D-1.1 .2 .1$ \\
\hline Tipos de alimentos/refeições & $\mathrm{FH}-1.2 .2 .2$ & Peso usual (PU) relatado & $A D-1.1 .2 .5$ \\
\hline Fórmula/solução de nutrição enteral & $\mathrm{FH}-1.3 .1 .1$ & Peso seco estimado & $A D-1.1 .2 .10$ \\
\hline Ingestão total de gordura & $\mathrm{FH}-1.5 .1 .1$ & Peso pré diálise & $A D-1.1 .2 .15$ \\
\hline Ingestão total de proteína & $\mathrm{FH}-1.5 .3 .1$ & Peso pós diálise & $A D-1.1 .2 .16$ \\
\hline Ingestão de proteína de alto valor biológico & $\mathrm{FH}-1.5 .3 .2$ & Ganho de peso & $A D-1.1 .4 .1$ \\
\hline Ingestão total de fibra & $\mathrm{FH}-1.5 .6 .1$ & Perda de peso & AD-1.1.4.2 \\
\hline Ingestão de potássio medida em 24 h & $\mathrm{FH}-1.6 .2 .2 .5$ & Percentagem de mudança de peso & AD-1.1.4.3 \\
\hline Ingestão de fósforo medida em 24 h & $\mathrm{FH}-1.6 .2 .2 .6$ & Ganho de peso interdialítico medido & AD-1.1.4.4 \\
\hline Prescrição de dieta modificada & $\mathrm{FH}-2.1 .1 .2$ & Índice de massa corporal & $A D-1.1 .5 .1$ \\
\hline Alergias alimentares & $\mathrm{FH}-2.1 .2 .5$ & Percentagem de gordura corporal & AD-1.1.7.1 \\
\hline Intolerância alimentar & $\mathrm{FH}-2.1 .2 .6$ & Circunferência muscular do braço & AD-1.1.7.9 \\
\hline Preferências alimentares & $\mathrm{FH}-4.3 .12$ & Dobra cutânea do tríceps & $A D-1.1 .7 .11$ \\
\hline Capacidade física para comer sozinho & $\mathrm{FH}-7.2 .2$ & Circunferência do braço & $A D-1.1 .7 .19$ \\
\hline
\end{tabular}


Continuação Tabela 1 - Termos de Avaliação e Reavaliação em Nutrição considerados essenciais por nutricionistas especialistas em doença renal.

\begin{tabular}{|c|c|c|c|}
\hline Categorias/Termos & Código & Tratamento & Código \\
\hline $\begin{array}{l}\text { DADOS BIOQUÍMICOS, TESTES E } \\
\text { PROCEDIMENTOS CLÍNICOS (BD) }\end{array}$ & & Obstipação & PD-1.1.5.9 \\
\hline Creatinina & BD-1.2.2 & Redução do apetite & PD-1.1.5.10 \\
\hline Taxa de filtração glomerular & BD-1.2.4 & Diarreia & PD-1.1.5.11 \\
\hline Sódio & BD-1.2.5 & Saciedade precoce & PD-1.1.5.12 \\
\hline Potássio & BD-1.2.7 & Dor epigástrica & PD-1.1.5.13 \\
\hline Cálcio, sérico & BD-1.2.9 & Azia & PD-1.1.5.18 \\
\hline Fósforo & BD-1.2.11 & Fezes líquidas & PD-1.1.5.22 \\
\hline Hormônio da paratireoide & BD-1.2.13 & Náusea & PD-1.1.5.24 \\
\hline Glicose, jejum & BD-1.5.1 & Vômito & PD-1.1.5.27 \\
\hline HgbA1c & BD-1.5.3 & Edema de pressão +1 & PD-1.1.6.1 \\
\hline Proteína C reativa & BD-1.6.1 & Edema de pressão +2 & PD-1.1.6.2 \\
\hline Colesterol, sérico & BD-1.7.1 & Edema de pressão +3 & PD-1.1.6.3 \\
\hline Colesterol, HDL & BD-1.7.2 & Edema de pressão +4 & PD-1.1.6.4 \\
\hline Colesterol, LDL & BD-1.7.3 & Anasarca & PD-1.1.6.5 \\
\hline Triglicerídeos, sérico & BD-1.7.7 & Edema de tornozelo & PD-1.1.6.6 \\
\hline Hemoglobina & BD-1.10.1 & Pé amputado & PD-1.1.7.1 \\
\hline Hematócrito & BD-1.10.2 & Mão amputada & PD-1.1.7.2 \\
\hline Ferritina, sérica & BD-1.10.10 & Perna amputada & PD-1.1.7.3 \\
\hline Ferro, sérico & BD-1.10.11 & Anuria & PD-1.1.9.2 \\
\hline Capacidade total de ligação do ferro & BD-1.10.12 & Alopecia & PD-1.1.10.2 \\
\hline Saturação da transferrina & BD-1.10.13 & Ageusia (perda de paladar) & PD-1.1.13.1 \\
\hline Albumina & BD-1.11.1 & Estomatite angular & PD-1.1.13.2 \\
\hline Volume urinário & BD-1.12.4 & Atrofia muscular & PD-1.1.14.1 \\
\hline Microalbumina na urina & BD-1.12.10 & Câimbra muscular & PD-1.1.14.3 \\
\hline Proteína na urina, 24 horas & BD-1.12.12 & Tontura & PD-1.1.16.12 \\
\hline ACHADOS FíSICOS FOCADOS EM NUTRIÇÃO (PD) & & Pele seca & PD-1.1.17.8 \\
\hline Astenia & PD-1.1.1.1 & Prurido da pele & PD-1.1.17.38 \\
\hline Obesidade & PD-1.1.1.10 & Desdentado & PD-1.1.18.10 \\
\hline Excesso de gordura subcutânea & PD-1.1.2.2 & Disfagia & PD-1.1.19.3 \\
\hline Perda de gordura subcutânea & PD-1.1.2.3 & Alteração da deglutição & PD-1.1.19.10 \\
\hline Adiposidade central & PD-1.1.2.4 & Pressão arterial & PD-1.1.21.1 \\
\hline Distensão abdominal & PD-1.1.5.3 & & \\
\hline HISTÓRIA DO CLIENTE* (CH) & & Imunológico (ex.: alergias alimentares) & $\mathrm{CH}-2.1 .8$ \\
\hline Idade & $\mathrm{CH}-1.1 .1$ & Tratamento/terapia clínica & $\mathrm{CH}-2.2 .1$ \\
\hline Gênero & $\mathrm{CH}-1.1 .2$ & Tratamento cirúrgico & $\mathrm{CH}-2.2 .2$ \\
\hline Sexo & $\mathrm{CH}-1.1 .3$ & Cuidado paliativo de fim de vida & $\mathrm{CH}-2.2 .3$ \\
\hline Mobilidade & $\mathrm{CH}-1.1 .12$ & Fatores socioeconômicos & $\mathrm{CH}-3.1 .1$ \\
\hline Queixa principal em nutrição do cliente & $\mathrm{CH}-2.1 .1$ & Apoio social e clínico & $\mathrm{CH}-3.1 .4$ \\
\hline Cardiovascular & $\mathrm{CH}-2.1 .2$ & $\begin{array}{l}\text { INSTRUMENTOS DE AVALIAÇÃO, } \\
\text { MONITORAMENTO E REAVALIAÇÃO (AT) }\end{array}$ & \\
\hline Gastrintestinal & $\mathrm{CH}-2.1 .5$ & $\begin{array}{l}\text { Classificação da Avaliação Subjetiva Global } \\
\text { (Subjective Global Assessment - SGA) }\end{array}$ & AT-1.1 \\
\hline
\end{tabular}

Nota: *Cliente, na terminologia padronizada, refere-se a indivíduos, grupos, populações, estruturas e indivíduos de apoio. 


\section{Recomendação 4}

Do total de 192 termos de Diagnóstico em Nutrição padronizados internacionalmente, 28 são recomendados para treinamento inicial de nutricionistas que trabalham com pacientes com DRC no Brasil.

Nível de evidência C, Força 1

\section{Comentários}

O diagnóstico em nutrição é rótulo de um problema específico que pode ser resolvido ou melhorado por meio da intervenção do nutricionista.

A adoção de linguagem diagnóstica é elemento importante e central da documentação, pois padroniza os termos utilizados para nomear os problemas ou necessidades de saúde do paciente ${ }^{56}$. Pelo fato de a TPCN ter iniciado com termos de diagnóstico, há estudos de validação nessa área. Um estudo inicial testou a validade do conteúdo ${ }^{57}$. Além disso, a validação foi realizada por nutricionistas especializados em pediatria ${ }^{58}$, gerontologia ${ }^{59}$ e oncologia ${ }^{60}$. Embora com sugestão de necessidade de refinamento, a terminologia foi considerada aceitável pelos profissionais. A Tabela 2 apresenta os termos selecionados pelos especialistas.

\section{Recomendação 5}

A definição de desnutrição energético-proteica pode ser padronizada para pacientes com DRC com foco na etiologia e relação com inflamação em: 1) associada à doença ou condição crônica com inflamação continuada; 2) associada à doença crônica com inflamação mínima ou não percebida; 3) associada à doença ou injúria aguda com inflamação grave, e 4) associada à baixa ingestão alimentar crônica pura não relacionada à doença.

Nível de evidência B, Força 1

\section{Comentários}

$\mathrm{Na}$ área da nefrologia, há grande número de definições para a desnutrição, como: desnutrição urêmica ${ }^{61}$, caquexia renal urêmica/caquexia urêmica ${ }^{62}$, sarcopenia renal ${ }^{63,64}$, síndrome MIA (desnutrição-inflamação e aterosclerose) ${ }^{65-68}$ ou síndrome do complexo desnutrição-inflamação (MICS), desnutrição proteico-energética ${ }^{69}$ e definhamento proteico energético (protein-energy wasting - PEW) ${ }^{70,71}$. Cada definição de desnutrição validada para esses pacientes inclui diferentes critérios. Portanto, as taxas de prevalência podem variar, e as possibilidades de comparação são limitadas. Além disso, com foco na padronização, a definição de desnutrição não

Tabela 2 - Termos de Diagnóstico em nutrição considerados essenciais por nutricionistas especialistas em doença renal crônica.

\begin{tabular}{|c|c|c|c|}
\hline Categorias/Termos & Código & Tratamento & Código \\
\hline INGESTÃO & & CLÍNICA - NC & \\
\hline Gasto energético aumentado & $\mathrm{Nl}-1.1$ & Mordedura/mastigação com dificuldade & NC-1.2 \\
\hline Ingestão de energia subótima & $\mathrm{Nl}-1.2$ & Função gastrintestinal alterada & NC-1.4 \\
\hline Ingestão de energia excessiva & $\mathrm{Nl}-1.3$ & $\begin{array}{l}\text { Valores laboratoriais relacionados à nutrição alterados } \\
\text { (especificar): }\end{array}$ & NC-2.2 \\
\hline Ingestão oral subótima & $\mathrm{Nl}-2.1$ & Baixo peso & NC-3.1 \\
\hline Ingestão de líquido excessiva & $\mathrm{Nl}-3.2$ & Perda de peso não intencional & NC-3.2 \\
\hline Ingestão proteico-energética subótima & $\mathrm{Nl}-5.2$ & Sobrepeso/obesidade & NC-3.3 \\
\hline Ingestão de gordura excessiva & $\mathrm{NI}-5.5 .2$ & Desnutrição (subnutrição) & NC-4.1 \\
\hline Ingestão de proteína subótima & $\mathrm{NI}-5.6 .1$ & Desnutrição relacionada à doença ou condição crônica & NC-4.1.2 \\
\hline Ingestão de proteína excessiva & $\mathrm{NI}-5.6 .2$ & $\begin{array}{l}\text { Desnutrição moderada relacionada à doença ou condição } \\
\text { crônica }\end{array}$ & NC-4.1.2.1 \\
\hline Ingestão de carboidrato excessiva & $\mathrm{NI}-5.8 .2$ & Desnutrição grave relacionada à doença ou condição crônica & NC-4.1.2.2 \\
\hline Ingestão de fibra subótima & $\mathrm{NI}-5.8 .5$ & Desnutrição moderada relacionada à doença ou injúria aguda & NC-4.1.3.1 \\
\hline Ingestão de mineral subótima (especificar): & $\mathrm{NI}-5.10 .1$ & Desnutrição grave relacionada à doença ou injúria aguda & NC-4.1.3.2 \\
\hline Ingestão de mineral excessiva (especificar): & $\mathrm{NI}-5.10 .2$ & COMPORTAMENTAL - AMBIENTAL - NB & \\
\hline Potássio & $\mathrm{NI}-5.10 .2 .5$ & Inatividade física & NB-2.1 \\
\hline Fósforo & $\mathrm{NI}-5.10 .2 .6$ & & \\
\hline
\end{tabular}


pode ser específica aos pacientes com DRC. Ou seja, para otimizar a prática e a pesquisa é essencial que sejam definidos termos e critérios validados, mas não somente para a população renal.

Dentre todas, a PEW e a sarcopenia são os termos mais comumente relacionados à desnutrição de pacientes com DRC. Na TPCN, a sarcopenia não é considerada diagnóstico em nutrição, mas relacionada a sinais e sintomas, obtidos na Avaliação e Reavaliação. O termo PEW não está incluído na TPCN e, pelo fato de ser utilizado apenas para pacientes com DRC, não é viável de ser incluído na SNOMED.

A TPCN define os diagnósticos de desnutrição em três categorias, baseadas na etiologia, de acordo com a proposta de padronização internacional da Academy/ ASPEN (American Society of Parenteral and Enteral Nutrition) de $2012^{72}$. O foco das etiologias é o processo inflamatório, que é comum na DRC e está estreitamente relacionado à desnutrição e mortalidade dos pacientes.

Em 2017, as diretrizes da ESPEN (European Society for Clinical Nutrition and Metabolism) ${ }^{73}$ foram um pouco mais refinadas, e propuseram classificar a desnutrição em quatro categorias: 1) associada à doença ou condição crônica com inflamação continuada; 2) associada à doença crônica com inflamação mínima ou não percebida; 3) associada à doença ou injúria aguda com inflamação grave, e 4) associada à baixa ingestão crônica pura não relacionada à doença. A definição e as classificações da ESPEN são aplicáveis a pacientes com DRC, em diversas fases da doença e locais de atendimento (ex.: clínicas, hospitais, ambulatórios). Portanto, podem ser recomendadas como padronização.

\section{Recomendação 6}

A Avaliação Subjetiva Global (ASG), conhecida como SGA (Subjective Global Assessment), é o instrumento de diagnóstico de desnutrição energético-proteica mais bem validado para pacientes com DRC. A MCC (Malnutrition Clinical Characteristics - Características Clínicas da Desnutrição) é um instrumento objetivo, validado para diferentes populações clínicas, e também pode ser recomendado para pacientes com DRC.

Nível de evidência A para SGA e B para MCC; Força 1

\section{Comentários}

Grande número de instrumentos de diagnóstico de desnutrição tem sido proposto e validado para pacientes com DRC. A SGA é um instrumento clássico e foi validada diversas vezes em todos os estágios da $\mathrm{DRC}^{74,75}$.
Além disso, a SGA tradicional deu origem a diversos outros instrumentos, como a Avaliação Subjetiva Global Pontuada Gerada pelo Paciente (Patient Generated - SGA, PG-SGA), validada para pacientes em $\mathrm{H}^{76}$, e com inclusão de dados específicos, como a SGA de Sete Pontos ${ }^{77,78}$. Esta é pontuada e desconsidera edema, inclui anos de diálise e presença de comorbidades. Outra derivação foi o Escore de Desnutrição-Inflamação (Malnutrition-Inflammation Score, MIS) ${ }^{78-83}$. Neste foram adicionados três itens: índice de massa corporal (IMC), albumina sérica e capacidade total de ligação do ferro.

Adicionalmente, a MAN Longa (Mini Nutritional Assessment Long-Form - MNA-LF) ${ }^{84,85}$ e o Escore de Competência Nutricional (Nutritional Competence Score, NCS) 86,87 também foram associados com a mortalidade de pacientes com DRC. O Escore Objetivo de Nutrição em Diálise (Objective Score of Nutrition on Dialysis, OSND) foi associado com a MIS ${ }^{88}$. Já o Escore Clínico Integrado de Nutrição em Diálise (Integrative Clinical Nutrition Dialysis Score, ICNDS) foi significativamente correlacionado com a SGA ${ }^{89}$. Os critérios da PEW também são utilizados para diagnóstico de desnutrição $0^{90}$ e associados à SGA e à mortalidade de pacientes em diálise ${ }^{91}$.

O KDOQI indica a SGA de Sete Pontos para pacientes com DRC em estágio 5 e sugere a MIS para pacientes em $\mathrm{HD}$ e pós-transplante ${ }^{36}$. Entretanto, por serem específicos para pacientes com DRC, esses instrumentos não atendem ao critério da universalidade. A TPCN recomenda, para qualquer população adulta, a SGA (Subjective Global Assessment), a PG-SGA e a MAN Longa. Tais instrumentos são indicados pela ESPEN ${ }^{73}$ para populações clínicas. Porém, quando se busca padronização, não é prática a utilização de diferentes instrumentos.

Embora haja busca incessante de adaptações ou desenvolvimento de novos instrumentos, a SGA tradicional é comum a todas as diretrizes, por ser validada em diferentes populações e locais de atendimento, mesmo quando modificada. A não aceitação universal da SGA pode dever-se à insegurança em relação à subjetividade.

A GLIM (Global Leadership Initiative on Malnutrition) ${ }^{92}$ envolveu as quatro maiores sociedades internacionais de nutrição clínica e desenvolveu um consenso sobre indicadores praticáveis para o diagnóstico de várias formas de desnutrição, em diferentes populações-alvo e locais. Nos critérios da GLIM, o mínimo de um indicador fenotípico e de um etiológico devem estar presente para diagnosticar a desnutrição. Os indicadores fenotípicos são perda de peso não voluntária, IMC baixo e massa muscular reduzida, e os etiológicos são ingestão alimentar ou assimilação de nutrientes reduzida e inflamação. A GLIM não tem objetivo de servir como instrumento de medida, mas como estrutura de diagnóstico. Entretanto, seus critérios ainda não foram 
validados, assim como seus pontos de corte para gravidade $^{93}$. Exceto para pacientes transplantados renais e para aqueles nos estágios iniciais da DRC, a inclusão e o ponto de corte do IMC podem gerar falta de especificidade. Um dos aspectos é que há evidências que demonstram relação contra epidemiológica (associação negativa) entre o IMC alto e a mortalidade para pacientes, particularmente em $\mathrm{HD}^{36}$. Ou seja, é difícil criar pontos de cortes diferentes de IMC para populações clínicas diversas. Por isso, o IMC pode não ser considerado um critério universal.

Um instrumento menos subjetivo do que a SGA é a $M C C^{72}$. Esta utiliza as três categorias de desnutrição baseada na etiologia (Quadro 4). A MCC não inclui IMC ou albumina sérica como indicadores, mas está de acordo com os critérios da GLIM e está baseada em definição consistente de desnutrição. Além disso, todos os indicadores incluídos na MCC foram apoiados pelo KDOQ|36 para avaliação de desnutrição de pacientes com DRC.

Estudos demonstraram acurácia satisfatória e concordância moderada para a MCC, comparada à SGA, em pacientes adultos hospitalizados ${ }^{94}$, graves em geral, em trauma ${ }^{95}$ e cirúrgicos ${ }^{96}$. Em relação a desfechos, a MCC foi capaz de prever maior tempo ${ }^{97}$ e custos mais altos ${ }^{98}$ de hospitalização. Em pacientes de cirurgia oncológica abdominal, o grau de desnutrição, avaliado pela MCC, foi associado com maior tempo de hospitalização, maior custo, mortalidade hospitalar mais elevada, complicações mais graves e taxas de readmissões mais altas ${ }^{99}$. Resultados semelhantes foram obtidos em estudos retrospectivos com pacientes hospitalizados em geral ${ }^{100,101}$. A desnutrição, avaliada pela MCC, também foi associada à mortalidade a longo prazo (até dois anos) em idosos com pneumonia ${ }^{102}$. Estudos em UTI demonstraram que a MCC foi preditora de morte e tempo de internação ${ }^{103,104}$. Estudo prospectivo resultou em validade concorrente e preditiva da MCC em 600 adultos e idosos hospitalizados, mesmo sem o uso da força de preensão palmar ${ }^{105}$. As causas de hospitalização foram, principalmente, enfermidades crônicas, como câncer, doenças cardíacas e pulmonares, e distúrbios gastrintestinais. A MCC teve boa concordância e acurácia satisfatória com a SGA para os desfechos de tempo de hospitalização, morte no hospital, readmissão e mortalidade em seis meses após a alta. Em pacientes idosos em cuidados de reabilitação pós enfermidade aguda, a MCC também foi associada com tempo de internação e capacidade funcional ${ }^{106}$.

Quadro 4 - Características clínicas da desnutrição para adultos, critérios da Academy e ASPEN.

\begin{tabular}{|c|c|c|c|c|c|c|c|c|c|c|c|c|}
\hline $\begin{array}{l}\text { Indicadores } \\
\text { Clínicos }\end{array}$ & \multicolumn{4}{|c|}{$\begin{array}{l}\text { Desnutrição Relacionada à } \\
\text { Doença ou Injúria Aguda }\end{array}$} & \multicolumn{4}{|c|}{$\begin{array}{l}\text { Desnutrição Relacionada à } \\
\text { Doença ou Condição Crônica }\end{array}$} & \multicolumn{4}{|c|}{$\begin{array}{c}\text { Desnutrição Relacionada a } \\
\text { Circunstâncias Sociais/Am- } \\
\text { bientais }\end{array}$} \\
\hline $\begin{array}{l}\text { 1. Redução } \\
\text { da Ingestão } \\
\text { Energética }\end{array}$ & \multicolumn{2}{|c|}{$\begin{array}{l}<75 \% \text { da necessi- } \\
\text { dade estimada de } \\
\text { energia por }>7 \text { dias }\end{array}$} & \multicolumn{2}{|c|}{$\begin{array}{l}\leq 50 \% \text { da necessi- } \\
\text { dade estimada de } \\
\text { energia por } \geq 5 \text { dias }\end{array}$} & \multicolumn{2}{|c|}{$\begin{array}{l}<75 \% \text { da necessi- } \\
\text { dade estimada de } \\
\text { energia por } \geq 1 \text { mês }\end{array}$} & \multicolumn{2}{|c|}{$\begin{array}{l}<75 \% \text { da necessi- } \\
\text { dade estimada de } \\
\text { energia por } \geq 1 \text { mês }\end{array}$} & \multicolumn{2}{|c|}{$\begin{array}{c}<75 \% \text { da neces- } \\
\text { sidade estimada } \\
\text { de energia por } \geq 3 \\
\text { meses }\end{array}$} & \multicolumn{2}{|c|}{$\begin{array}{l}\leq 50 \% \text { da necessi- } \\
\text { dade estimada de } \\
\text { energia por } \geq 1 \text { mês }\end{array}$} \\
\hline $\begin{array}{l}\text { 2. Perda } \\
\text { de Peso }\end{array}$ & $\begin{array}{c}\% \\
1-2 \\
5 \\
7,5\end{array}$ & $\begin{array}{l}\text { Tempo } \\
1 \text { sem } \\
1 \text { mês } \\
3 \text { meses }\end{array}$ & $\begin{array}{c}\% \\
>1-2 \\
>5 \\
>7,5\end{array}$ & $\begin{array}{l}\text { Tempo } \\
1 \text { sem } \\
1 \text { mês } \\
3 \text { meses }\end{array}$ & $\begin{array}{c}\% \\
5 \\
7,5 \\
10 \\
20\end{array}$ & $\begin{array}{l}\text { Tempo } \\
1 \text { mês } \\
3 \text { meses } \\
6 \text { meses } \\
1 \text { ano }\end{array}$ & $\begin{array}{c}\% \\
>5 \\
>7,5 \\
>10 \\
>20\end{array}$ & $\begin{array}{l}\text { Tempo } \\
1 \text { mês } \\
3 \text { meses } \\
6 \text { meses } \\
1 \text { ano }\end{array}$ & $\begin{array}{c}\% \\
5 \\
7,5 \\
10 \\
20\end{array}$ & $\begin{array}{l}\text { Tempo } \\
1 \text { mês } \\
3 \text { meses } \\
6 \text { meses } \\
1 \text { ano }\end{array}$ & $\begin{aligned} & \% \\
&>5 \\
&>7,5 \\
&>10 \\
&>20\end{aligned}$ & $\begin{array}{l}\text { Tempo } \\
1 \text { mês } \\
3 \text { meses } \\
6 \text { meses } \\
1 \text { ano }\end{array}$ \\
\hline $\begin{array}{l}\text { 4. Perda de } \\
\text { Massa } \\
\text { Muscular }\end{array}$ & \multicolumn{2}{|c|}{ Leve } & \multicolumn{2}{|c|}{ Moderada } & \multicolumn{2}{|c|}{ Leve } & \multicolumn{2}{|c|}{ Grave } & \multicolumn{2}{|c|}{ Leve } & \multicolumn{2}{|c|}{ Grave } \\
\hline $\begin{array}{l}\text { 5. Acúmulo } \\
\text { de Líquido }\end{array}$ & \multicolumn{2}{|c|}{ Leve } & \multicolumn{2}{|c|}{ Moderada a grave } & \multicolumn{2}{|c|}{ Leve } & \multicolumn{2}{|c|}{ Grave } & \multicolumn{2}{|c|}{ Leve } & \multicolumn{2}{|c|}{ Grave } \\
\hline $\begin{array}{l}\text { 6. Força de } \\
\text { Preensão } \\
\text { Palmar }\end{array}$ & \multicolumn{2}{|c|}{ - } & \multicolumn{2}{|c|}{ Reduzida } & & & \multicolumn{2}{|c|}{ Reduzida } & \multicolumn{4}{|c|}{ Reduzida } \\
\hline
\end{tabular}

Nota: *Pelo menos dois indicadores ou características clínicas devem estar presentes para o diagnóstico da desnutrição.

Adaptado do Consensus statement: Academy of Nutrition and Dietetics and American Society for Parenteral and Enteral Nutrition: characteristics recommended for the identification and documentation of adult malnutrition (undernutrition), $2012^{72}$. 
De nosso conhecimento, não há estudos publicados sobre a MCC aplicada em pacientes com DRC. Porém, em análise de estudos disponíveis, é provável que o instrumento seja validado para essa população.

\section{Recomendação 7}

Do total de 385 termos de Intervenção em Nutrição padronizados internacionalmente, 9 são recomendados para treinamento inicial de nutricionistas que trabalham com pacientes com DRC no Brasil.

Nível de evidência C, Força 1

\section{Comentários}

A Tabela 3 demonstra os termos de Intervenção em Nutrição selecionados pelos especialistas. A etapa de Intervenção em Nutrição do PCN é um conjunto de comportamentos e ações específicos, executados, delegados, coordenados ou recomendados pelo nutricionista ${ }^{53}$. A intervenção direciona o paciente para a resolução ou melhoria do problema. Ela tem duas fases inter-relacionadas: plano e implementação.

O plano inclui a prescrição dietética e as metas de intervenção em nutrição. Estas devem, preferencialmente, ser determinadas entre o nutricionista e o paciente. As metas devem ser alcançáveis, mensuráveis e priorizarem os diagnósticos em nutrição a serem trabalhados. Para a definição do plano, devem ser consultadas diretrizes de prática baseada em evidência e outros guias que determinam resultados esperados, focados no indivíduo, para cada diagnóstico em nutrição. No plano também são definidos tempo e frequência do cuidado e os recursos necessários para alcançar as metas estabelecidas.

Na fase da implementação, o nutricionista determina as intervenções, seleciona estratégias apropriadas, discute com o paciente e executa o plano. Baseado no problema, define duração e monitoramento, e desenvolve materiais adicionais.
Diversas estratégias de intervenção podem ser indicadas para o paciente com DRC, principalmente com o objetivo de prevenir ou reverter a desnutrição. A educação e o aconselhamento em nutrição, individualizados e contínuos, são intervenções essenciais para a prevenção de desnutrição e desequilíbrios de líquido, vitaminas e minerais de pacientes com DRC ${ }^{107}$.

\section{Recomendação 8}

As diretrizes KDOQI Nutrição são recomendadas como padrão de referência para a ingestão diária de nutrientes para pacientes com DRC. Os instrumentos Meu Prato, Pirâmide Mediterrânea e Plano de Dieta DASH podem ser recomendados como padrão de referência para alimentos e podem ser adaptados para os diversos estágios da DRC. Metas individuais devem ser estabelecidas de acordo com o julgamento profissional.

Nível de evidência B, Força 1

\section{Comentários}

O padrão de referência para a ingestão diária de nutrientes serve como guia para as etapas de Avaliação e Reavaliação (análise de adequação quantitativa) e de Intervenção (plano e prescrição de dieta) no PCN. O nutricionista pode identificar o padrão de referência mais apropriado ou definir uma meta individualizada, definida a partir do julgamento profissional.

Para indivíduos saudáveis e para situações clínicas que não possuem estudos que embasam recomendações específicas de nutrientes, o padrão de referência mais utilizado no mundo são as DRls (Dietary Reference Intakes) 108-114. Para pacientes metabolicamente estáveis com DRC, este consenso recomenda o Clinical Practice Guideline for Nutrition in Chronic Disease ${ }^{36}$ (Quadro 5) como padrão de referência para a ingestão diária de nutrientes. As diretrizes são parte do programa KDOQI, desenvolvido pela National Kidney Foundation e pela Academy.

Tabela 3 - Termos de Intervenção em nutrição considerados essenciais por nutricionistas especialistas em doença renal.

\begin{tabular}{llll}
\hline Categorias/Termos & Código & \multicolumn{1}{c}{ Categorias/Termos } & Código \\
\hline $\begin{array}{l}\text { OFERTA DE ALIMENTO E/OU } \\
\text { NUTRIENTE (ND) }\end{array}$ & ND-1.2.2.1 & Dieta com redução de potássio & ND-1.2.11.5.2 \\
\hline Dieta com aumento de energia & ND-1.2.3.2 & Dieta com redução de fósforo & ND-1.2.11.6.2 \\
Dieta com aumento de proteína & ND-1.2.4.3 & Dieta com redução de sódio & ND-1.2.11.7.2 \\
Dieta com redução de carboidrato & ND-1.2.4.3.2 & Mudança na composição da nutrição enteral & ND-2.1.1 \\
Dieta com redução de carboidrato simples & & &
\end{tabular}


Quadro 5 - Referência para ingestão diária de nutrientes para pacientes com doença renal crônica.

\begin{tabular}{llcl}
\hline Energia e Nutrientes & Não Dialítica & Hemodiálise & Diálise Peritoneal \\
\hline $\begin{array}{l}\text { Energia (kcal/kg de peso atual ou } \\
\begin{array}{l}\text { ideal, em caso de obesidade ou } \\
\text { muito baixo peso) }\end{array}\end{array}$ & $25-35$ & $25-35$ & $25-35$ \\
& & (dieta + dialisado) \\
\hline
\end{tabular}

Proteínas (kcal/kg de peso atual ou ideal, em caso de obesidade ou muito baixo peso)
0,55-0,60 com dieta mista ou 0,28-0,43 com dieta vegetariana + 0,28-0,43 com suplementação de aminoácidos essenciais ou cetoácidos.

Pacientes com diabetes: 0,6-0,8
$1,0-1,2 \quad 1,0-1,2$

\begin{tabular}{llll}
\hline Sódio $(\mathrm{mg})$ & $<2.300$ & $<2.300$ & $<2.300$ \\
\hline Potássio $(\mathrm{mg})$ & $\begin{array}{l}\text { Ajustada para manter níveis } \\
\text { séricos normais }\end{array}$ & $\begin{array}{l}\text { Ajustada para manter } \\
\text { níveis séricos normais }\end{array}$ & $\begin{array}{l}\text { Ajustada para manter } \\
\text { níveis séricos normais }\end{array}$ \\
\hline Líquidos $(\mathrm{mL})^{\mathrm{a}}$ & Geralmente sem restrição & Ajustada para ganho de \\
& $\begin{array}{l}\text { peso interdialítico } \\
\text { (ideal: 2,5-4\%) }\end{array}$ & Geralmente sem restrição \\
\hline Fósforo $(\mathrm{mg})$ & $\begin{array}{l}\text { Ajustada para manter níveis } \\
\text { séricos normais }\end{array}$ & $\begin{array}{l}\text { Ajustada para manter } \\
\text { níveis séricos normais }\end{array}$ & $\begin{array}{l}\text { Ajustada para manter } \\
\text { níveis séricos normais }\end{array}$ \\
\hline Cálcio $(\mathrm{mg})$ & $\begin{array}{l}\text { Se não em uso de vitamina D: } 800-1.000 \\
\text { (incluindo dieta, suplementação } \\
\text { e quelantes à base de cálcio) }\end{array}$ & $\begin{array}{l}\text { Ajustada (dieta, suplemen- } \\
\text { tação e quelante à base de } \\
\text { cálcio) considerando o uso } \\
\text { de vitamina D, para manter } \\
\text { níveis séricos normais }\end{array}$ & $\begin{array}{l}\text { Ajustada para manter } \\
\text { níveis séricos normais }\end{array}$
\end{tabular}

Adaptado de KDOQI, 202036; aOpinião.

Instrumentos como o Meu Prato, a Pirâmide da Dieta Mediterrânea ${ }^{115}$ e o Plano de Dieta DASH (Dietary Approaches to Stop Hypertension) podem ser utilizados como referência para a ingestão diária de alimentos para a DRC nos estágios 1-5. Os mesmos instrumentos podem ser facilmente adaptados para as recomendações de pacientes em HD ou DP.

\section{Recomendação 9}

Do total de 991 termos de Monitoramento e Aferição em Nutrição padronizados internacionalmente, 94 são recomendados para treinamento inicial de nutricionistas que trabalham em pacientes com DRC no Brasil.

Nível de evidência C, Força 1

\section{Comentários}

A etapa do Monitoramento e Aferição em Nutrição é o último passo do $\mathrm{PCN}^{53}$. É composta de três componentes: monitoramento, mensuração e aferição de mudanças nos sinais e sintomas (indicadores da Avaliação e Reavaliação).

Monitoramento e Aferição em Nutrição examina os resultados após a intervenção, seleciona indicadores de qualidade derivados de diretrizes de boa prática, baseados em evidência ${ }^{53}$. Os indicadores usam dados disponíveis para fornecer medidas quantitativas para alcançar as metas objetivadas. Na etapa do Monitoramento e Aferição é definido se a Reavaliação é necessária ${ }^{53}$.

Os termos padronizados para Monitoramento e Aferição em Nutrição são os mesmos usados no passo Avaliação e Reavaliação (Tabela 1), exceto aqueles específicos da História do Cliente (50 termos). 


\section{RECOMENDAÇÕES PARA O SISTEMA DE GESTÃO DE RESULTADOS}

\section{Recomendação 10}

O acrômio ADIMA (Avaliação, Diagnóstico, Intervenção, Monitoramento e Aferição) é recomendado para documentar o Processo de Cuidado em Nutrição de pacientes com DRC.

Nível de evidência C, Força 1

\section{Comentários}

O PCN requer documentação, que é uma fonte de dados necessária para monitorar e avaliar o cuidado, além de apoiar o sistema de gestão de resultados. A documentação em formatação padronizada otimiza a gestão da qualidade; ou seja, facilita a avaliação da produtividade.

O formato que utiliza acrômio ADIMA segue os componentes: "Avaliação/Reavaliação (A), Diagnóstico (D), Intervenção (I) e Monitoramento/Aferição (M/A)"39. Na parte "D", é indicado o formato PES, que deve citar o problema (P), a etiologia $(E)$ e os sinais e sintomas $(S)^{39}$. Seguido do título do problema, deve estar o termo "relacionado a", já que é importante identificar a causa. A etiologia (causa) é composta pelos fatores que contribuem para a existência do problema.

A identificação da etiologia leva à seleção de uma intervenção, cujo objetivo é resolver o problema em nutrição. Os sinais e sintomas (indicadores) são aqueles que definiram se o paciente apresenta determinado diagnóstico em nutrição. Eles estão ligados à etiologia pelas palavras "conforme evidenciado pelo (a)".

O formato com uso do acrômio ADIMA não é oficialmente padronizado para a documentação do PCN, mas é sugerido, visto que é prático e fácil. Independentemente do formato, a documentação deve ser clara e concisa, específica, limitada a um único problema de cada vez, precisamente relacionada a uma etiologia e baseada nas informações coletadas na avaliação em nutrição. Deve utilizar o mínimo de texto livre, para facilitar comparativos e análises de indicadores de desempenho.

\section{Recomendação 11}

A gestão de resultados deve focar, principalmente, na desnutrição, que pode ser separada por faixas de idade. Outros indicadores diretamente relacionados com intervenções em nutrição são: ganho de peso interdialítico, fósforo, cálcio, vitamina $25(\mathrm{OH}) \mathrm{D}$, potássio, bicarbonato séricos e glicemia ou hemoglobina glicada.

Nível de evidência A, Força 1

\section{Comentários}

O Sistema de Gestão de Resultados também é uma estrutura de suporte do $\mathrm{PCN}^{53}$, pois pode ser operado por indivíduos de diversas profissões. Ele é responsável pela melhoria contínua da qualidade e é extremamente importante em qualquer ambiente de cuidado.

Um Sistema de Gestão de Resultados define indicadores que refletem a situação atual de um problema e os compara com o ideal ou com uma meta estabelecida, que seja realista para a melhoria. Metas devem ser identificadas de acordo com a realidade de cada instituição. Elas precisam desafiadoras e possíveis de serem alcançadas. Além disso, devem ser constantemente ajustadas (revisadas) para os resultados obtidos.

Cálculos e comparações de indicadores de gestão identificam ações a serem tomadas para a melhoria da qualidade dos serviços prestados. Indicadores essenciais e específicos em nutrição devem refletir o que pode ser melhorado, exclusivamente, pelo trabalho do nutricionista. Considera-se que há diversos outros indicadores que devem ser trabalhados em conjunto com a equipe multiprofissional, para oportunidades de melhoria geral dos serviços.

A padronização da TPCN em prontuários eletrônicos permite a documentação em formato estruturado. Para a tarefa, há instrumentos publicados de fluxo de trabalho, tanto para adultos como para pediatria ${ }^{116}$. A entrada de dados com o mínimo ou sem texto livre (prontuário estruturado) permite o acesso rápido, não são ambíguos ou inespecíficos e são, usualmente, definidos dentro de parâmetros baseados em evidência. Portanto, facilita a gestão de resultados, aumenta a eficiência dos cuidados e melhora a eficácia de desfechos em nutrição ${ }^{45}$.

O Sistema de Gestão de Resultados monitora o sucesso da implementação do PCN e proporciona subsídios de orientação. O objetivo é a otimização dos serviços, com foco na qualidade, eficácia e eficiência dos processos. Os instrumentos de gestão possibilitam a verificação de conformidades e não conformidades. $\bigcirc$ Quadro 6 inclui itens geralmente disponíveis na prática profissional com pacientes com DRC e estreitamente relacionados com $\circ \mathrm{PCN}$. A maioria tem importância reconhecida pelo KDOQI ${ }^{36}$ e está recomendada em diretrizes da American Diabetes Association ${ }^{117}$. Pelo fato de a desnutrição ser de alto risco nessa população, é sugerido que seja analisada em termos de gravidade e em diferentes faixas etárias. 
Quadro 6 - Indicadores de gestão da qualidade recomendados para o cuidado em nutrição de pacientes com doença renal crônica.

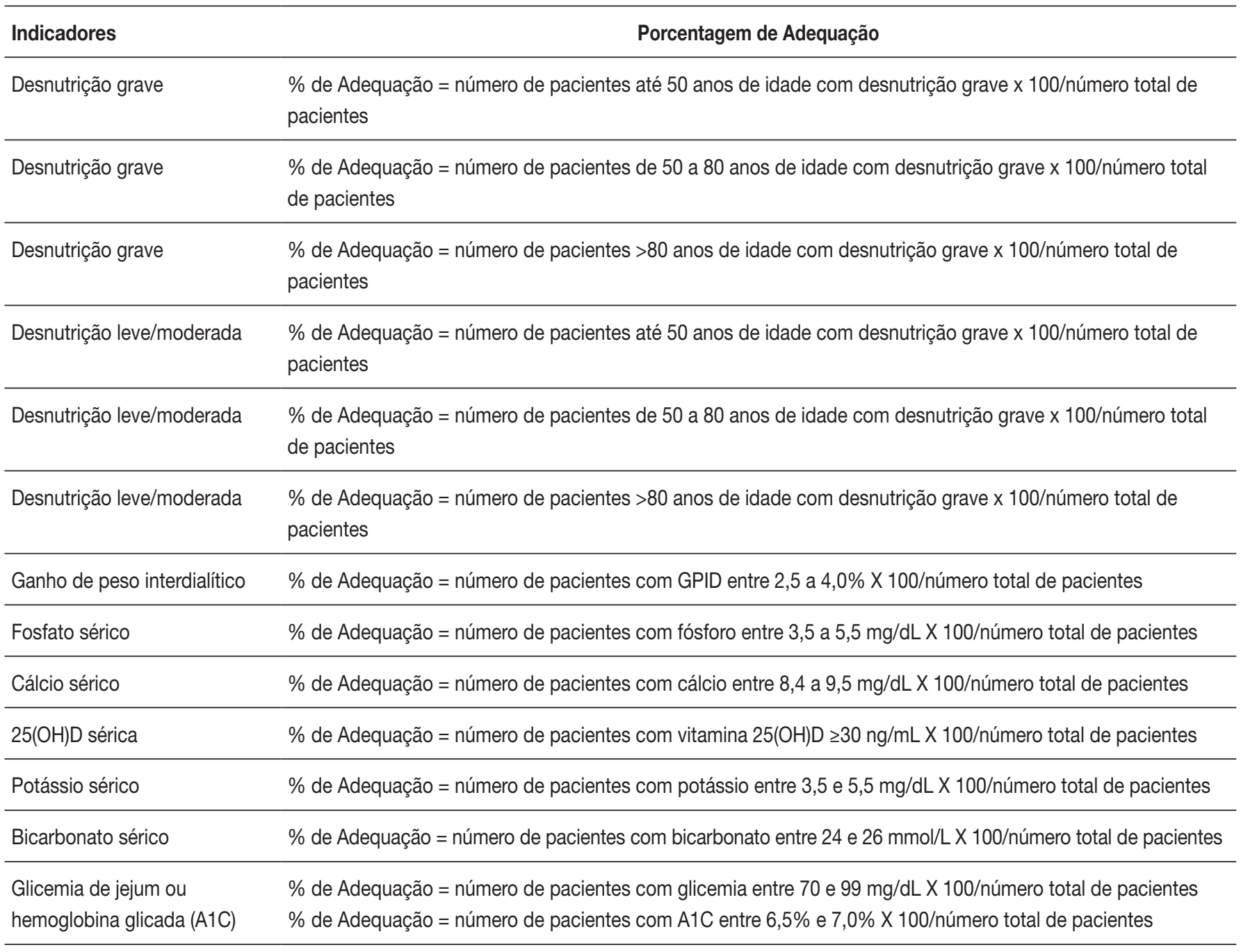

Adaptado de KDOQI, 202036, American Diabetes Association, $2019^{117}$ e Opinião.

\section{CONCLUSÃO}

A padronização da terminologia não significa que o cuidado deva ser igual para todos os pacientes. Sempre haverá necessidade de personalização, que leva em conta as necessidades e valores individuais, com a utilização das melhores evidências disponíveis para a tomada de decisões.

Por outro lado, a padronização proporciona mudanças inevitáveis na prática. Ela é importante para os principais julgamentos clínicos, além de facilitar a documentação e a gestão de resultados relacionados ao cuidado em nutrição. A padronização facilita a informatização na coleta e na análise de dados. Portanto, facilita a intersecção entre a tecnologia, a prática e a pesquisa.

Após a curva inicial de aprendizado, a implementação da TPCN e de instrumentos de triagem e de avaliação é uma grande oportunidade de melhoria na eficácia dos serviços em nutrição. Ela pode assegurar a qualidade do cuidado, promover melhorias no atendimento e nos desfechos, melhorar a comunicação entre profissionais e instituições, otimizar o estabelecimento de prioridades no planejamento de intervenções, facilitar a escolha de objetivos realistas e mensuráveis, auxiliar na documentação em prontuários, ajudar na gestão dos serviços e na compreensão dos resultados, facilitar o pagamento de serviços, identificar contribuições específicas do nutricionista no cuidado da saúde e melhorar a visibilidade deste profissional na equipe e na comunidade.

Em suma, a padronização em nutrição significa grandes avanços na prática, na educação relacionada, na pesquisa e em regulamentações. Certamente é o meio mais eficaz para demonstrar a influência do cuidado em nutrição na saúde de indivíduos com DRC. 


\section{REFERÊNCIAS}

1. Piccoli GB, Lippi F, Fois A, Gendrot L, Nielsen L, Vigreux J, et al. Intradialytic nutrition and hemodialysis prescriptions: a personalized stepwise approach. Nutrients. 2020;12(3):785.

2. Koppe L, Fouque D, Kalantar-Zadeh K. Kidney cachexia or protein-energy wasting in chronic kidney disease: facts and numbers. J Cachexia Sarcopenia Muscle. 2019;10(3):479-84.

3. Oliveira EA, Zheng R, Carter CE, Mak RH. Cachexia/protein energy wasting syndrome in CKD: causation and treatment. Semin Dial. 2019;32(6):493-9.

4. Levey AS, Eckardt KU, Dorman NM, Christiansen SL, Hoorn EJ, Ingelfinger JR, et al. Nomenclature for kidney function and disease report of a Kidney Disease: Improving Global Outcomes (KDIGO) Consensus Conference. Kidney Int. 2020;97(6):1117-29.

5. Grant JS, Davis LL. Selection and use of content experts for instrument development. Res Nurs Health. 1997;20(3):269-74.

6. Davis LL. Instrument review: getting the most from a panel of experts. Appl Nurs Res. 1992;5(4):194-7.

7. Polit DF, Beck CT. The content validity index: are you sure you know what's being reported? Critique and recommendations. Res Nurs Health. 2006;29(5):489-97.

8. Lynn MR. Determination and quantification of content validity. Nurs Res. 1986;35(6):382-5.

9. Guyatt GH, Oxman AD, Vist GE, Kunz R, Falck-Ytter Y, AlonsoCoello P, et al; GRADE Working Group. GRADE: an emerging consensus on rating quality of evidence and strength of recommendations. BMJ. 2008;336(7650):924-6.

10. Skipper A, Coltman A, Tomesko J, Charney P, Porcari J, Piemonte TA, et al. Position of the Academy of Nutrition and Dietetics: Malnutrition (Undernutrition) Screening Tools for All Adults. J Acad Nutr Diet. 2020;120(4):709-13.

11. Field LB, Hand RK. Differentiating malnutrition screening and assessment: a nutrition care process perspective. J Acad Nutr Diet. 2015;115(5):824-8.

12. Komatsu M, Okazaki M, Tsuchiya K, Kawaguchi H, Nitta K. Geriatric nutritional risk index is a simple predictor of mortality in chronic hemodialysis patients. Blood Purif. 2015;39(4):281-7.

13. Kang SH, Cho KH, Park JW, Yoon KW, Do JY. Geriatric Nutritional Risk Index as a prognostic factor in peritoneal dialysis patients. Perit Dial Int. 2013;33(4):405-10.

14. Führ LM, Wazlawik E, Garcia MF. The predictive value of composite methods of nutritional assessment on mortality among haemodialysis patients. Clin Nutr ESPEN. 2015;10(1):e21-5.

15. Xia YA, Healy A, Kruger R. Developing and validating a renal nutrition screening tool to effectively identify undernutrition risk among renal inpatients. J Ren Nutr. 2016;26(5):299-307.

16. Skipper A, Coltman A, Tomesko J, Charney P, Porcari J, Piemonte $\mathrm{TA}$, et al. Adult malnutrition (undernutrition) screening: an evidence analysis center systematic review. J Acad Nutr Diet. 2020;120(4):669-708.

17. Abbott J, Teleni L, McKavanagh D, Watson J, McCarthy A, Isenring E. A novel, automated nutrition screening system as a predictor of nutritional risk in an oncology day treatment unit (ODTU). Support Care Cancer. 2014;22(8):2107-12.

18. Arribas L, Hurtós L, Sendrós MJ, Peiró I, Salleras N, Fort E, et al. NUTRISCORE: a new nutritional screening tool for oncological outpatients. Nutrition. 2017;33:297-303.

19. Bell JJ, Bauer JD, Capra S. The malnutrition screening tool versus objective measures to detect malnutrition in hip fracture. J Hum Nutr Diet. 2013;26(6):519-26.

20. Ferguson ML, Bauer J, Gallagher B, Capra S, Christie DR, Mason BR. Validation of a malnutrition screening tool for patients receiving radiotherapy. Australas Radiol. 1999;43(3):325-7.

21. Gabrielson DK, Scaffidi D, Leung E, Stoyanoff L, Robinson J, Nisenbaum R, et al. Use of an abridged scored Patient-Generated Subjective Global Assessment (abPG-SGA) as a nutritional screening tool for cancer patients in an outpatient setting. Nutr Cancer. 2013;65(2):234-9.

22. Isenring E, Cross G, Daniels L, Kellett E, Koczwara B. Validity of the malnutrition screening tool as an effective predictor of nutritional risk in oncology outpatients receiving chemotherapy. Support Care Cancer. 2006;14(11):1152-6.

23. Isenring EA, Bauer JD, Banks M, Gaskill D. The Malnutrition Screening Tool is a useful tool for identifying malnutrition risk in residential aged care. J Hum Nutr Diet. 2009;22(6):545-50.

24. Isenring EA, Banks M, Ferguson M, Bauer JD. Beyond malnutrition screening: appropriate methods to guide nutrition care for aged care residents. J Acad Nutr Diet. 2012;112(3):376-81.

25. Lawson CS, Campbell KL, Dimakopoulos I, Dockrell ME. Assessing the validity and reliability of the MUST and MST nutrition screening tools in renal inpatients. J Ren Nutr. 2012;22(5):499-506.

26. Nor Azian MZ, Suzana S, Romzi MA. Sensitivity, specificity, predictive value and inter-rater reliability of malnutrition screening tools in hospitalised adult patients. Malays J Nutr. 2014;20(2):209-19.

27. Nursal TZ, Noyan T, Atalay BG, Köz N, Karakayali H. Simple two-part tool for screening of malnutrition. Nutrition. 2005;21(6):659-65.

28. Shaw C, Fleuret C, Pickard JM, Mohammed K, Black G, Wedlake L. Comparison of a novel, simple nutrition screening tool for adult oncology inpatients and the Malnutrition Screening Tool (MST) against the Patient-Generated Subjective Global Assessment (PG-SGA). Support Care Cancer. 2015;23(1):47-54.

29. Ulltang M, Vivanti AP, Murray E. Malnutrition prevalence in a medical assessment and planning unit and its association with hospital readmission. Aust Health Rev. 2013;37(5):636-41.

30. Wu ML, Courtney MD, Shortridge-Baggett LM, Finlayson K, Isenring EA. Validity of the malnutrition screening tool for older adults at high risk of hospital readmission. J Gerontol Nurs. 2012;38(6):38-45.

31. Young AM, Kidston S, Banks MD, Mudge AM, Isenring EA. Malnutrition screening tools: comparison against two validated nutrition assessment methods in older medical inpatients. Nutrition. 2013;29(1):101-6.

32. Abe Vicente M, Barão K, Silva TD, Forones NM. What are the most effective methods for assessment of nutritional status in outpatients with gastric and colorectal cancer? Nutr Hosp. 2013;28(3):585-91.

33. Hogan D, Lan LT, Diep DT, Gallegos D, Collins PF. Nutritional status of Vietnamese outpatients with chronic obstructive pulmonary disease. J Hum Nutr Diet. 2017;30(1):83-9.

34. Marshall S, Young A, Bauer J, Isenring E. Nutrition screening in geriatric rehabilitation: criterion (concurrent and predictive) validity of the Malnutrition Screening Tool and the Mini Nutritional Assessment-Short Form. J Acad Nutr Diet. 2016;116(5):795-801.

35. Neelemaat F, Meijers J, Kruizenga H, van Ballegooijen H, van Bokhorst-de van der Schueren M. Comparison of five malnutrition screening tools in one hospital inpatient sample. J Clin Nurs. 2011;20(15-16):2144-52.

36. Ikizler TA, Burrowes JD, Byham-Gray LD, Campbell KL, Carrero JJ, Chan W, et al. KDOQI clinical practice guideline for nutrition in CKD: 2020 update. Am J Kidney Dis. 2020;76(3 Suppl 1):S1-S107.

37. Di Bela A, Croisier E, Blake C, Pelecanos A, Bauer J, Brown T. Assessing the concurrent validity and interrater reliability of patient-led screening using the malnutrition screening tool in the ambulatory cancer care outpatient setting. J Acad Nutr Diet. 2020;120(7):1210-5.

38. Ferguson M, Capra S, Bauer J, Banks M. Development of a valid and reliable malnutrition screening tool for adult acute hospital patients. Nutrition. 1999;15(6):458-64. 
39. Academy of Nutrition and Dietetics. Nutrition Terminology Reference Manual (eNCPT): Dietetics language for nutrition care. International collaboration and translations. [cited 2020 September 4]. Available from: http://www.ncpro.org/ international-collaboration

40. Swan WI, Pertel DG, Hotson B, Lloyd L, Orrevall Y, Trostler $\mathrm{N}$, et al. Nutrition Care Process (NCP) update part 2: developing and using the ncp terminology to demonstrate efficacy of nutrition care and related outcomes. J Acad Nutr Diet. 2019;119(5):840-55.

41. Hakel-Smith N, Lewis NM,Eskridge KM. Orientation to nutrition care process standards improves nutrition care documentation by nutrition practitioners. J Am Diet Assoc. 2005;105(10):1582-9.

42. Lövestam E, Boström AM, Orrevall Y. Nutrition care process implementation: experiences in various dietetics environments in Sweden. J Acad Nutr Diet. 2017;117(11):1738-48.

43. Lövestam E, Orrevall Y, Koochek A, Anderson A. The struggle to balance system and lifeworld: Swedish dietitians' experiences of a standardised nutrition care process and terminology. Health Sociol Rev. 2016;25(3):240-55.

44. Myers EF, Trostler N, Varsha V, Voet H. Insights from the diabetes in India Nutrition Guidelines Study: adopting innovations using a knowledge transfer model. Top Clin Nutr. 2017;32(1):69-86.

45. Rossi M, Campbell KL, Ferguson M. Implementation of the Nutrition Care Process and International Dietetics and Nutrition Terminology in a single-center hemodialysis unit: comparing paper vs electronic records. J Acad Nutr Diet. 2014;114(1):124-30.

46. Thompson KL, Davidson P, Swan WI, Hand RK, Rising C, Dunn AV, et al. Nutrition care process chains: the "missing link" between research and evidence-based practice. J Acad Nutr Diet. 2015;115(9):1491-8.

47. Tilakavati K, Reinhard T, Shanthi K, Shy-Pyng T, Chee-Hee S. Incorporating the Nutrition Care Process model into dietetics internship evaluation: a Malaysian university experience. Nutr Diet. 2016;73:283-95.

48. Enrione EB, Reed D, Myers EF. Limited agreement on etiologies and signs/symptoms among registered dietitian nutritionists in clinical practice. J Acad Nutr Diet. 2016;116(7):1178-86.

49. Carpenter A, Mann J, Yanchis D, Campbell A, Bannister L, Vresk L. Implementing a clinical practice change: adopting the nutrition care process. Can J Diet Pract Res. 2019;80(3):127-30.

50. Hand RK, Murphy WJ, Field LB, Lee JA, Parrott JS, Ferguson $\mathrm{M}$, et al. Validation of the Academy/A.S.P.E.N. Malnutrition Clinical Characteristics. J Acad Nutr Diet. 2016;116(5):856-64.

51. Murphy WJ, Yadrick MM, Steiber AL, Mohan V, Papoutsakis C. Academy of Nutrition and Dietetics Health Informatics Infrastructure (ANDHII): a pilot study on the documentation of the nutrition care process and the usability of ANDHII by Registered Dietitian Nutritionists. J Acad Nutr Diet. 2018;118(10):1966-74.

52. Papoutsakis C, Moloney L, Sinley RC, Acosta A, Handu D, Steiber AL. Academy of Nutrition and Dietetics Methodology for Developing Evidence-Based Nutrition Practice Guidelines. J Acad Nutr Diet. 2017;117(5):794-804.

53. Swan WI, Vivanti A, Hakel-Smith NA, Hotson B, Orrevall Y, Trostler N, et al. Nutrition care process and model update: toward realizing people-centered care and outcomes management. J Acad Nutr Diet. 2017;117(12):2003-14.

54. Dent LA, McDuffie I. A survey of the utilization of the nutrition care process for documentation in outpatient dialysis centers. Meeting Abstracts. J Ren Nutr. 2011(1):205-7.

55. Associação Brasileira de Nutrição; Fidelix MSP, organizadores. Manual orientativo: sistematização do cuidado de nutrição. São Paulo: Asbran; 2014.

56. Hakel-Smith N, Lewis NM. A standardized nutrition care process and language are essential components of a conceptual model to guide and document nutrition care and patient outcomes. J Am Diet Assoc. 2004;104(12):1878-84.
57. Enrione EB. Content validation of nutrition diagnoses. Top Clin Nutr. 2008;23(4):306-19.

58. Soares L, Auslander MH, Enrione EB. Application of the International Dietetics and Nutrition Terminology for Nutrition Diagnosis among Board Certified Specialists in Pediatric Nutrition. J Acad Nutr Diet. 2015:A-22.

59. Ritter-Gooder PK, Lewis NM, Eskridge KM. Content validation of a standardized language diagnosis by certified specialists in gerontological nutrition. J Am Diet Assoc. 2011;111(4):561-6.

60. EnrioneEB, Villar J. Content validation of two nutrition diagnosis commonly identified in oncology patients. J Acad Nutr Diet. 2013:A-13.

61. Klaric D, Žepina M, Klaric V. Malnutrition in patients on dialysis treatment. Acta Med Croatica. 2016;70(Supl. 2):55-7.

62. Ruperto M, Sánchez-Muniz FJ, Barril G. A clinical approach to the nutritional care process in protein-energy wasting hemodialysis patients. Nutr Hosp. 2014;29(4):735-50.

63. Tangvoraphonkchai K, Hung R, Sadeghi-Alavijeh O, Davenport A. Differences in prevalence of muscle weakness (sarcopenia) in haemodialysis patients determined by hand grip strength due to variation in guideline definitions of sarcopenia. Nutr Clin Pract. 2018;33(2):255-60.

64. Hirai K, Ookawara S, Morishita Y. Sarcopenia and physical inactivity in patients with chronic kidney disease. Nephrourol Mon. 2016;8(3):e37443.

65. Bergström J, Lindholm B. Malnutrition, cardiac disease, and mortality: an integrated point of view. Am J Kidney Dis. 1998;32(5):834-41.

66. Efendic E, Lindholm B, Bergström J, Stenvinkel P. Strong connection between malnutrition, inflammation and arteriosclerosis. Improved treatment of renal failure if underlying factors are attacked. Lakartidningen. 1999;96(42):4538-42.

67. Stenvinkel P, Heimbürger O, Paultre F, Diczfalusy U, Wang T, Berglund L, et al. Strong association between malnutrition, inflammation, and atherosclerosis in chronic renal failure. Kidney Int. 1999;55(5):1899-911.

68. Pertosa G, Simone S, Soccio M, Marrone D, Grandaliano G. Chronic inflammation and cardiovascular risk in hemodialysis. G Ital Nefrol. 2003;20(6):631-40.

69. Alvarenga LA, Andrade BD, Moreira MA, Nascimento RP, Macedo ID, Aguiar AS. Nutritional profile of hemodialysis patients concerning treatment time. J Bras Nefrol. 2017;39(3):283-6.

70. Pérez-Torres A, González Garcia ME, San José-Valiente B, Bajo Rubio MA, Celadilla Diez O, López-Sobaler AM, et al. Proteinenergy wasting syndrome in advanced chronic kidney disease: prevalence and specific clinical characteristics. Nefrologia. 2018;38(2):141-51.

71. Hasheminejad N, Namdari M, Mahmoodi MR, Bahrampour A, Azmandian J. Association of handgrip strength with malnutrition-inflammation score as an assessment of nutritional status in hemodialysis patients. Iran J Kidney Dis. 2016;10(1):30-5.

72. White JV, Guenter P, Jensen G, Malone A, Shofield M. Academy of Nutrition and Dietetics Malnutrition Work Group; A.S.P.E.N. Malnutrition Task Force; A.S.P.E.N. Board of Directors. Consensus statement of the Academy of Nutrition and Dietetics/American Society for Parenteral and Enteral Nutrition: characteristics recommended for the identification and documentation of adult malnutrition (undernutrition). J Acad Nutr Diet. 2012;112(5):730-8.

73. Cederholm T, Barazzoni R, Austin P, Ballmer P, Biolo G, Bischoff $\mathrm{SC}$, et al. ESPEN guidelines on definitions and terminology of clinical nutrition. Clin Nutr. 2017;36(1):49-64.

74. Dai L, Mukai H, Lindholm B, Heimbürger O, Barany P, Stenvinkel $\mathrm{P}$, et al. Clinical global assessment of nutritional status as predictor of mortality in chronic kidney disease patients. PLoS One. 2017;12(12):e0186659. 
75. Paudel K, Visser A, Burke S, Samad N, Fan SL. Can bioimpedance measurements of lean and fat tissue mass replace subjective global assessments in peritoneal dialysis patients? J Ren Nutr. 2015;25(6):480-7.

76. Desbrow B, Bauer J, Blum C, Kandasamy A, McDonald A, Montgomery K. Assessment of nutritional status in hemodialysis patients using patient-generated subjective global assessment. J Ren Nutr. 2005;15(2):211-6.

77. Kalantar-ZadehK, KleinerM,DunneE,LeeGH,LuftFC.Amodified quantitative subjective global assessment of nutrition for dialysis patients. Nephrol Dial Transplant. 1999;14(7):1732-8.

78. Santin F, Rodrigues J, Brito FB, Avesani CM. Performance of subjective global assessment and malnutrition inflammation score for monitoring the nutritional status of older adults on hemodialysis. Clin Nutr. 2018;37(2):604-11.

79. Kalantar-Zadek K, Kopple JD, Block G, Humphreys MH. A malnutrition-inflammation score is correlated with morbidity and mortality in maintenance hemodialysis patients. Am J Kidney Dis. 2001;38(6):1251-63.

80. Borges MC, Vogt BP, Martin LC, Caramori JC. Malnutrition Inflammation Score cut-off predicting mortality in maintenance hemodialysis patients. Clin Nutr ESPEN. 2017;17:63-7.

81. Wang WL, Liang S, Zhu FL, Liu JQ, Chen XM, Cai GY. Association of the malnutrition-inflammation score with anthropometry and body composition measurements in patients with chronic kidney disease. Ann Palliat Med. 2019;8(5):596-603.

82. Aggarwal HK, Jain D, Chauda R, Bhatia S, Sehgal R. Assessment of malnutrition inflammation score in different stages of chronic kidney disease. Pril (Makedon Akad Nauk Umet Odd Med Nauki). 2018;39(2-3):51-61.

83. CupistiA,D'Alessandro C, CaselliGM, forGroupM.I.TO.-DP:; Egidi MF, Bottai A, et al. Nutritional and Functional assessment of peritoneal dialysis patients in the clinical practice: Report from MITO-DP Group. G Ital Nefrol. 2016;33(4):gin/33.4.6.

84. Erdoğan E, Tutal E, Uyar ME, Bal Z, Demirci BG, Sayin B, et al. Reliability of bioelectrical impedance analysis in the evaluation of the nutritional status of hemodialysis patients: a comparison with Mini Nutritional Assessment. Transplant Proc. 2013;45(10):3485-8.

85. Rogowski L, Kusztal M, Golebiowski T, Bulińska K, ZembrońLacny A, Wyka J, et al. Nutritional assessment of patients with end-stage renal disease using the MNA scale. Adv Clin Exp Med. 2018;27(8):1117-23.

86. Thijssen S, Wong MM, Usvyat LA, Xiao Q, Kotanko P, Maddux FW. Nutritional competence and resilience among hemodialysis patients in the setting of dialysis initiation and hospitalization. Clin J Am Soc Nephrol. 2015;10(9):1593-601.

87. Ye X, Dekker MJE, Maddux FW, Kotanko P, Konings CJAM, Raimann JG, et al. Dynamics of nutritional competence in the last year before death in a large cohort of us hemodialysis patients. J Ren Nutr. 2017;27(6):412-20.

88. Beberashvili I, Azar A, Sinuani I, Yasur H, Feldman L, Averbukh $\mathrm{Z}$, et al. Objective Score of Nutrition on Dialysis (OSND) as an alternative for the malnutrition-inflammation score in assessment of nutritional risk of haemodialysis patients. Nephrol Dial Transplant. 2010;25(8):2662-71.

89. BenyaminiSB, KatzirZ, BiroA, Cernes R, Shalev B, Chaimy T, et al. Nutrition assessment and risk prediction in dialysis patientsa new integrative score. J Ren Nutr. 2014;24(6):401-10.

90. Fouque D, Kalantar-Zadeh K, Kopple J, Cano N, Chauveau $\mathrm{P}$, Cuppari L, et al. A proposed nomenclature and diagnostic criteria for protein-energy wasting in acute and chronic kidney disease. Kidney Int. 2008;73(4):391-8.

91. Leinig CE, Moraes T, Ribeiro S, Riella MC, Olandoski M, Martins C, et al. Predictive value of malnutrition markers for mortality in peritoneal dialysis patients. J Ren Nutr. 2011;21(2):176-83.
92. Cederholm T, Jensen GL, Correia MITD, Gonzalez MC, Fukushima R, Higashiguchi T, et al. GLIM criteria for the diagnosis of malnutrition: a consensus report from the global clinical nutrition community. Clin Nutr. 2019;38(1):1-9.

93. Keller H, de van der Schueren MAE, GLIM Consortium; Jensen GL, Barazzoni R, Compher C, Correia MITD, et al. Global Leadership Initiative on Malnutrition (GLIM): Guidance on validation of the operational criteria for the diagnosis of protein-energy malnutrition in adults. JPEN J Parenter Enteral Nutr. 2020;44(6):992-1003.

94. Hipskind P, Rath M, JeVenn A, Galang M, Nawaya A, Smith E, et al. Correlation of new criteria for malnutrition assessment in hospitalized patients: AND-ASPEN Versus SGA. J Am Coll Nutr. 2020;39(6):518-27.

95. Ceniccola GD, Okamura AB, Sepúlveda Neta JDS, Lima FC, Santos de Deus AC, Oliveira JA, et al. Association between AND-ASPEN malnutrition criteria and hospital mortality in critically ill trauma patients: a prospective cohort study. JPEN J Parenter Enteral Nutr. 2020.

96. Abahuje E, Niyongombwa I, Karenzi D, Bisimwa JA, Tuyishime E, Ntirenganya F, et al. Malnutrition in acute care surgery patients in Rwanda. World J Surg. 2020;44(5):1361-7.

97. Guerra RS, Fonseca I, Pichel F, Restivo MT, Amaral TF. Usefulness of six diagnostic and screening measures for undernutrition in predicting length of hospital stay: a comparative analysis. J Acad Nutr Diet. 2015;115(6):927-38.

98. Guerra RS, Sousa AS, Fonseca I, Pichel F, Restivo MT, Ferreira $\mathrm{S}$, et al. Comparative analysis of undernutrition screening and diagnostic tools as predictors of hospitalisation costs. J Hum Nutr Diet. 2016;29(2):165-73.

99. Mosquera C, Koutlas NJ, Edwards KC, Strickland A, Vohra NA, Zervos EE, et al. Impact of malnutrition on gastrointestinal surgical patients. J Surg Res. 2016;205(1):95-101.

100. Hiller LD, Shaw RF, Fabri PJ. Difference in composite end point of readmission and death between malnourished and nonmalnourished Veterans assessed using Academy of Nutrition and Dietetics/American Society for Parenteral and Enteral Nutrition Clinical Characteristics. JPEN J Parenter Enteral Nutr. 2017;41(8):1316-24.

101. Hudson L, Chittams J, Griffith C, Compher C. Malnutrition identified by Academy of Nutrition and Dietetics/American Society for Parenteral and Enteral Nutrition is associated with more 30-day readmissions, greater hospital mortality, and longer hospital stays: a retrospective analysis of nutrition assessment data in a major medical center. JPEN J Parenter Enteral Nutr. 2018;42(5):892-7.

102. Yeo HJ, Byun KS, Han J, Kim JH, Lee SE, Yoon SH, et al. Prognostic significance of malnutrition for long-term mortality in community-acquired pneumonia: a propensity score matched analysis. Korean J Intern Med. 2019;34(4):841-9.

103. Ceniccola GD, Holanda TP, Pequeno RSF, Mendonça VS, Oliveira ABM, Carvalho LSF, et al. Relevance of AND-ASPEN criteria of malnutrition to predict hospital mortality in critically ill patients: a prospective study. J Crit Care. 2018;44:398-403.

104. Hiura G, Lebwohl B, Seres DS. Malnutrition diagnosis in critically ill patients using 2012 Academy of Nutrition and Dietetics/American Society for Parenteral and Enteral Nutrition standardized diagnostic characteristics is associated with longer hospital and intensive care unit length of stay and increased in-hospital mortality. JPEN J Parenter Enteral Nutr. 2020;44(2):256-64.

105. Burgel CF, Teixeira PP, Leites GM, Carvalho GD, Modanese PVG, Rabito EI, et al. Concurrent and Predictive Validity of AND-ASPEN Malnutrition Consensus is satisfactory in hospitalized patients: a longitudinal study. JPEN J Parenter Enteral Nutr. 2020.

106. Sánchez-Rodriguez D, Marco E, Ronquillo-Moreno N, Maciel-Bravo L, Gonzales-Carhuancho A, Duran X, et al. 
ASPEN-AND-ESPEN: A postacute-care comparison of the basic definition of malnutrition from the American Society of Parenteral and Enteral Nutrition and Academy of Nutrition and Dietetics with the European Society for Clinical Nutrition and Metabolism definition. Clin Nutr. 2019;38(1):297-302.

107. ObiY,QaderH,KovesdyCP,Kalantar-ZadehK.Latestconsensus and update on protein-energy wasting in chronic kidney disease. Curr Opin Clin Nutr Metab Care. 2015;18(3):254-62.

108. National Academy of Sciences. Dietary references intakes for calcium, phosphorus, magnesium, vitamin $\mathrm{D}$, and fluoride. Washington: National Academy Press; 1997.

109. National Academy of Sciences. Dietary references intakes for thiamine, riboflavin, niacin, vitamin B6, folate, vitamin B12, pantothenic acid, biotin, and choline. Washington: National Academy Press; 1998.

110. National Academy of Sciences. Dietary references intakes for vitamin C, vitamin E, selenium, and carotenoids. Washington: National Academy Press; 2000.

111. National Academy of Sciences. Dietary references intakes for vitamin A, vitamin K, arsenic, boron, chromium, copper, iodine, iron, manganese, molybdenum, nickel, silicon, vanadium, and zinc. Washington: National Academy Press; 2001.
112. National Academy of Sciences. Dietary references intakes for energy, carbohydrate, fiber, protein and amino acids. Washington: National Academy Press; 2002.

113. National Academy of Sciences. Dietary reference intakes for water, potassium, sodium, chloride, and sulfate. Washington: National Academy Press; 2004.

114. National Academy of Sciences. Dietary references intakes for calcium and vitamin D. Washington: National Academy Press; 2011.

115. Serra-Majem L, Ortiz-Andrellucchi A, Sánchez-Villegas A. Mediterranean diet. Encyclopedia of Food Security and Sustainability. 2019;2:292-301.

116. Kight CE, Bouche JM, Curry A, Frankenfield D, Good K, Guenter P, et al; Academy of Nutrition and Dietetics; American Society for Parenteral and Enteral Nutrition; Association of Clinical Documentation Improvement Specialists. Consensus Recommendations for Optimizing Electronic Health Records for Nutrition Care. J Acad Nutr Diet. 2020;120(7):1227-37.

117. American Diabetes Association. 6. Glycemic targets: standards of medical care in diabetes-2019. Diabetes Care. 2019;42(Suppl 1):S61-S70. 